\title{
ANALISA KUAT DUKUNG PONDASI BORED PILE BERDASARKAN DATA PENGUJIAN LAPANGAN (CONE DAN N-STANDARD PENETRATION TEST)
}

\author{
Ulfa Jusi \\ Jurusan Teknik Sipil Sekolah Tinggi Teknologi Pekanbaru \\ Jalan Dirgantara No. 4 Arengka Raya Pekanbaru \\ E-mail : ulfajusi@gmail.com
}

\begin{abstract}
Abstrak
Pondasi merupakan suatu pekerjaan yang sangat penting dalam suatu pekerjaan teknik sipil, karena pondasi inilah yang memikul dan menahan suatu beban yang bekerja diatasnya yaitu beban konstruksi atas. Tujuan dari studi ini untuk menghitung kuat dukung tiang bored pile dari hasil sondir dan standar penetrasi test (SPT) kemudian membandingkan hasil kuat dukung tiang bored pile. Metode perhitungan kuat dukung untuk data sondir menggunakan metode Schmertmann dan Nottingham serta metode Meyerhoff, untuk data SPT menggunakan metode O'Neil dan Reese, metode Meyerhoff, metode Coyle dan Castello. Berdasarkan data sondir diperoleh hasil perhitungan dari metode Schmertmann dan Nottingham titik sondir S-3 $Q_{u}=2026,44$ $\mathrm{kN}$, dengan metode Meyerhoff diperoleh $\mathrm{Q}_{\mathrm{u}}=2276,20 \mathrm{kN}$. Sementara untuk data SPT diperoleh hasil perhitungan dari metode O'Neil dan Reese $\mathrm{Q}_{\mathrm{u}}=476,21 \mathrm{kN}$, metode Meyerhoff $\mathrm{Q}_{\mathrm{u}}=1948,87 \mathrm{kN}$ dan metode Coyle dan Castello $\mathrm{Q}_{\mathrm{u}}=734,37 \mathrm{kN}$. Dari hasil perhitungan kapasitas kuat dukung bored pile dari data sondir, metode Schertmann dan Nottingham lebih optimis, begitu pula metode O'Neil dan Reese untuk data N-SPT dengan safety factor yang relatif kecil.
\end{abstract}

Kata kunci : Bore pile, kapasitas dukung, N-SPT, sondir

\begin{abstract}
The foundation is a work that is critically important in a civil engineering job, because this is the foundation that bears and withstand a load thereon bekerjaa that construction loads above. The purpose of this study to calculate the strong support pole sondir bored pile of results and Standard Penetration Test (SPT) and then compare the results robust pile bearing bored pile. Strong support for the calculation method using the data sondir Schmertmann, Nottingham and methods Meyerhoff, for SPT data using methods O'Neil dan Reese, Meyerhoff methods and methods Coyle and Castello. Based on data from the calculation results obtained sondir Schmertman \& Nottingham point method sondir S-3 Qu = $2026.44 \mathrm{kN}$, the method Meyerhoff obtained $Q u=2276.20 \mathrm{kN}$. As for the SPT data obtained from the calculation results O'Neil dan Reese method Qu $=476.21 \mathrm{kN}$, Meyerhoff method $Q u=1948.87 \mathrm{kN}$ and methods of Coyle dan Castello $Q u=734.37 \mathrm{kN}$. From the calculation of the carrying capacity of bored pile strong sondir data, methods and Nottingham Schertmann more optimistic, as well as methods for data $O^{\prime}$ Neil dan Reese $N$-SPT with a relatively small safety factor.
\end{abstract}

Keywords : Bore pile, capacity support, $N$-SPT, sondir 


\section{A. PENDAHULUAN}

Secara umum permasalahan pondasi dalam lebih rumit dari pondasi dangkal. Pondasi bored pile adalah suatu pondasi yang dibangun dengan cara mengebor tanah terlebih dahulu, baru kemudian diisi dengan tulangan dan dicor. Bored pile dipakai apabila tanah dasar yang kokoh yang mempunyai daya dukung besar terletak sangat dalam, yaitu kurang lebih $15 \mathrm{~m}$ serta keadaan sekitar tanah bangunan sudah banyak berdiri bangunan-bangunan besar seperti gedung-gedung bertingkat sehingga dikhawatirkan dapat menimbulkan retak-retak pada bangunan yang sudah ada akibat getaran-getaran yang ditimbulkan oleh kegiatan pemancangan apabila dipakai pondasi tiang pancang. Kuat dukung bored pile diperoleh dari kuat dukung ujung (end bearing capacity), yang diperoleh dari tekanan ujung tiang dan kuat dukung geser atau selimut (friction bearing capacity) yang diperoleh dari kuat dukung gesek atau gaya adhesi antara bored pile dan tanah disekelilingnya. Bored pile berinteraksi dengan tanah untuk menghasilkan kuat dukung yang mampu memikul dan memberikan keamanan pada struktur atas. Untuk menghasilkan kuat dukung yang akurat maka diperlukan suatu penyelidikan tanah yang akurat juga. Ada dua metode yang biasa digunakan dalam penentuan kapasitas kuat dukung bored pile yaitu dengan menggunakan metode statis dan metode dinamis.

Penyelidikan tanah dengan menggunakan metode statis adalah penyelidikan sondir dan standard penetrasi test (SPT). Penyelidikan sondir bertujuan untuk mengetahui perlawanan penetrasi konus dan hambatan lekat tanah yang merupakan indikasi dari kekuatan kuat dukung lapisan tanah dengan menggunakan rumus empiris.

Penyelidikan standard penetrasi test (SPT) bertujuan untuk mendapatkan gambaran lapisan tanah berdasarkan jenis dan warna tanah melalui pengamatan secara visual, sifat-sifat tanah, karakteristik tanah.

Perencanaan pondasi bored pile mencakup rangkaian kegiatan yang dilaksanakan dengan berbagai tahapan yang meliputi studi kelayakan dan perencanaan teknis. Semua itu dilakukan supaya menjamin hasil akhir suatu konstruksi yang kuat, aman serta ekonomis.

Tujuan dari studi ini adalah :

1. Menghitung kuat dukung pondasi bored pile tunggal dari :

a. Data hasil sondir (Cone Penetration Test)

b. Data hasil Standart Penetration Test

2. Membandingkan hasil kuat dukung bored pile tunggal dengan metode penyelidikan dari data sondir (Cone Penetration Test) dan Standart Penetration Test (SPT)

\section{B. TINJAUAN PUSTAKA \\ 1. Umum}

Pondasi dalam adalah pondasi yang meneruskan beban bangunan ke tanah keras atau batu yang terletak jauh dari permukaan. Pondasi bored pile adalah pondasi yang dipasang ke dalam tanah dengan cara mengebor tanah terlebih dahulu, baru kemudian diisi tulangan dan dicor beton. Tiang ini biasanya dipakai pada tanah yang stabil dan kaku, sehingga memungkinkan untuk membentuk lubang yang stabil dengan alat bor. Jika tanah mengandung air, pipa besi dibutuhkan untuk menahan dinding lubang dan pipa ini ditarik ke atas pada waktu pengecoran beton. Pada tanah yang keras atau batuan lunak, dasar tiang dapat dibesarkan untuk menambah tahanan dukung ujung tiang. 


\section{Kapasitas Kuat Dukung Bored Pile dari Hasil Sondir}

Diantara perbedaan tes dilapangan, sondir atau cone penetration test (CPT) seringkali sangat dipertimbangkan berperanan dari geoteknik. Cone penetration test (CPT) atau sondir ini dapat juga mengklasifikasi lapisan tanah dan dapat memperkirakan kekuatan dan karakteristik dari tanah. Didalam perencanaan pondasi tiang, data tanah sangat diperlukan dalam merencanakan kapasitas daya dukung bearing capacity) dari bored pile sebelum pembangunan dimulai, guna menentukan kapasitas daya dukung ultimit dari pondasi tiang.

Untuk menghitung kuat dukung bored pile berdasarkan data hasil pengujian sondir dapat dilakukan dengan menggunakan :

a. Metode Aoki dan De Alencar

Kuat dukung ultimit pondasi bored pile dinyatakan dengan rumus :

$$
\mathrm{Q}_{\mathrm{u}}=\left(\mathrm{q}_{\mathrm{b}} \times \mathrm{A}_{\mathrm{b}}\right)
$$

Keterangan :

$\mathrm{Q}_{\mathrm{ult}} \quad=$ Kapasitas daya dukung bored pile $(\mathrm{kN})$

$\mathrm{qb}=$ Tahanan ujung sondir $\left(\mathrm{kN} / \mathrm{m}^{2}\right)$

$\mathrm{A}_{\mathrm{b}} \quad=$ Luas penampang tiang $\left(\mathrm{m}^{2}\right)$

Aoki dan Alencar mengusulkan untuk memperkirakan kapasitas dukung ultimit dari data sondir. Kapasitas dukung ujung persatuan luas $\left(\mathrm{q}_{\mathrm{b}}\right)$ diperoleh sebagai berikut:

$$
\mathrm{q}_{\mathrm{b}}=\frac{\mathrm{q}_{\mathrm{ca}}(\text { base })}{\mathrm{F}_{\mathrm{b}}}
$$

Keterangan :

$\mathrm{q}_{\mathrm{ca}}($ base $)=$ Perlawanan konus rata-rata $1,5 \mathrm{D}$ di atas ujung tiang, $1,5 \mathrm{D}$ di bawah ujung tiang

$\mathrm{F}_{\mathrm{b}}=$ Faktor empirik yang tergantung pada tipe tanah

Tabel 1. Faktor empirik $F_{b}$

\begin{tabular}{lc}
\hline \multicolumn{1}{c}{ Tipe Tiang Pancang } & $\mathrm{F}_{\mathrm{b}}$ \\
\hline Bored pile & 3,5 \\
Baja & 1,75 \\
Beton Pratekan & 1,75 \\
\hline
\end{tabular}

(Sumber : Titi \& Farsakh, 1999)

Pada perhitungan kapasitas pondasi bored pile dengan sondir tidak diperhitungkan kuat dukung selimut bored pile. Hal ini dikarenakan perlawanan geser tanah yang terjadi pada pondasi bored pile dianggap sangat kecil sehingga dianggap tidak ada. Untuk memperoleh kapasitas ijin tiang, maka diperlukan untuk membagi kapasitas ultimit dengan faktor aman tertentu.

Untuk dasar tiang yang dibesarkan dengan $\mathrm{d}<2 \mathrm{~m}$ :

$$
\mathrm{Q}_{\mathrm{a}}=\frac{\mathrm{Q}_{\mathrm{u}}}{2,5}
$$

Untuk dasar tiang tanpa pembesaran di bagian bawah :

$$
\mathrm{Q}_{\mathrm{a}}=\frac{\mathrm{Q}_{\mathrm{u}}}{2}
$$


b. Metode Schmertmann dan Nottingham

Kuat dukung ultimit neto $\left(\mathrm{Q}_{\mathrm{u}}\right)$, dihitung dengan persamaan :

$\mathrm{Q}_{\mathrm{u}}=\mathrm{A}_{\mathrm{b}} \mathrm{f}_{\mathrm{b}}+\mathrm{A}_{\mathrm{s}} \mathrm{f}_{\mathrm{s}}$

atau

$\mathrm{Q}_{\mathrm{u}}=\mathrm{A}_{\mathrm{b}} \omega \mathrm{q}_{\mathrm{ca}}+\mathrm{A}_{\mathrm{s}} \mathrm{K}_{\mathrm{f}} \mathrm{q}_{\mathrm{f}}$

Keterangan :

$\mathrm{A}_{\mathrm{b}}=$ Luas penampang tiang $\left(\mathrm{cm}^{2}\right)$

$\mathrm{A}_{\mathrm{s}}=$ Luas selimut tiang $\left(\mathrm{cm}^{2}\right)$

$\mathrm{f}_{\mathrm{b}} \quad=$ Tahanan ujung satuan $\left(\mathrm{kg} / \mathrm{cm}^{2}\right)$

$\mathrm{f}_{\mathrm{S}}=$ Tahanan gesek satuan $\left(\mathrm{kg} / \mathrm{cm}^{2}\right)$

$\mathrm{q}_{\mathrm{ca}}=$ Tahanan konus rata-rata $\left(\mathrm{kg} / \mathrm{cm}^{2}\right)$

$\mathrm{qf}_{\mathrm{f}} \quad=$ Tahanan gesek sisi konus $\left(\mathrm{kg} / \mathrm{cm}^{2}\right)$

$\mathrm{K}_{\mathrm{f}}=$ Koefisien tak berdimensi

$\omega=$ Koefisien korelasi

1). Tahanan ujung satuan

Dalam metode Schmertmann dan Nottingham (1975) tahanan ujung tiang per satuan luas, diperoleh dari nilai rata-rata $\mathrm{q}_{\mathrm{c}}$ disepanjang $8 \mathrm{~d}$ diatas dasar tiang sampai $0,7 \mathrm{~d}$ atau $4 \mathrm{~d}$ di bawah tiang. Langkah-langkah penentuan $\mathrm{q}_{\mathrm{ca}}$ adalah sebagai berikut :

a). Perhatikan diagram tahanan kerucut $\left(\mathrm{q}_{\mathrm{c}}\right)$ per kedalamannya dan pilihlah kedalaman sementara yang dianggap mendekati kapasitas ultimit bahan tiang yang dipakai.

b). Pada kedalaman tiang yang ditinjau, perhatikan tahanan konus rata-rata $\left(\mathrm{q}_{\mathrm{c}}\right)$ diambil pada jarak 8d di atas kedalaman ujung tiang dan $4 \mathrm{~d}$ di bawahnya.

c). Tentukan $\mathrm{q}_{\mathrm{c} 1}$ dengan menghitung nilai rata-rata tahanan kerucut $\left(\mathrm{q}_{\mathrm{c}}\right)$ di sepanjang garis patah-patah pada zona $8 \mathrm{~d}$ di atas dasar tiang. Lintasan garis patah-patah menunjukkan pengambilan nilai-nilai $\mathrm{q}_{\mathrm{c}}$ yang mewakili dan diperkirakan aman.

d). Telusuri lintasan garis patah-patah sedalam $4 d$ di bawah tiang. Tentukan $\mathrm{q}_{\mathrm{c} 2}$ dengan menghitung $\mathrm{q}_{\mathrm{c}}$ rata-rata di sepanjang garis tersebut.

e). Hitung $\mathrm{q}_{\mathrm{ca}}=1 / 2\left(\mathrm{q}_{\mathrm{c} 1}+\mathrm{q}_{\mathrm{c} 2}\right)$

f). Dengan menggunakan nilai-nilai dalam tabel 2 , tentukan $\omega$ guna memperhatikan pengaruh kadar kerikil atau OCR.

g). Hitung tahanan ujung satuan dengan persamaan :

$$
\mathrm{f}_{\mathrm{b}}=\omega \mathrm{q}_{\mathrm{ca}} \leq 150 \mathrm{~kg} / \mathrm{cm}^{2}\left(15.000 \mathrm{kN} / \mathrm{m}^{2}\right)
$$

Keterangan :

$\mathrm{f}_{\mathrm{b}}=$ Tahanan ujung satuan $\left(\mathrm{kg} / \mathrm{cm}^{2}\right)$

$\omega=$ Koefisien korelasi yang bergantung pada OCR (tabel 2)

$\mathrm{q}_{\mathrm{ca}}=1 / 2\left(\mathrm{q}_{\mathrm{c} 1}+\mathrm{q}_{\mathrm{c} 2}\right)\left(\mathrm{kg} / \mathrm{cm}^{2}\right)$

$\mathrm{q}_{\mathrm{c} 1}=\mathrm{q}_{\mathrm{c}}$ rata-rata pada zona $0,7 \mathrm{~d}$ atau $4 \mathrm{~d}$ di bawah dasar tiang $\left(\mathrm{kg} / \mathrm{cm}^{2}\right)$

$\mathrm{q}_{\mathrm{c} 2}=\mathrm{q}_{\mathrm{c}}$ rata-rata pada zona $8 \mathrm{~d}$ di atas dasar tiang $\left(\mathrm{kg} / \mathrm{cm}^{2}\right)$ 
Tabel 2. Faktor $\omega$ (deRuiter dan Beringen, 1979)

\begin{tabular}{lc}
\hline \multicolumn{1}{c}{ Kondisi Tanah } & Faktor $\omega$ \\
\hline Pasir terkonsolidasi normal $(\mathrm{OCR}=1)$ & 1 \\
\hline $\begin{array}{l}\text { Pasir mengandung banyak kerikil kasar; } \\
\text { Pasir dengan OCR }=\text { 2 sampai } 4\end{array}$ & 0,67 \\
\hline Kerikil halus; pasir dengan OCR = 6 sampai 10 & 0,5 \\
\hline
\end{tabular}

(Sumber : Bowles, 1996)

2). Tahanan gesek satuan

$$
\mathrm{f}_{\mathrm{s}}=\mathrm{K}_{\mathrm{f}} \mathrm{q}_{\mathrm{f}}\left(\mathrm{kg} / \mathrm{cm}^{2}\right)
$$

Keterangan :

$\mathrm{f}_{\mathrm{S}}=$ Tahanan gesek satuan $\left(\mathrm{kg} / \mathrm{cm}^{2}\right)$, nilainya dibatasi sampai $1,2 \mathrm{~kg} / \mathrm{cm}^{2}$ $(120 \mathrm{kPa})$

$\mathrm{q}_{\mathrm{f}}=$ Tahanan gesek sisi konus (sleeve friction) $\left(\mathrm{kg} / \mathrm{cm}^{2}\right)$

$\mathrm{K}_{\mathrm{f}} \quad=$ Koefisien tak berdimensi

Bila tiang dalam pasir, $\mathrm{K}_{\mathrm{f}}$ bergantung pada rasio $\mathrm{L} / \mathrm{d}(\mathrm{L}=$ kedalaman, dan $\mathrm{d}=$ diameter tiang). Di dalam kedalaman $8 \mathrm{~d}$ pertama dari permukaan tanah, $\mathrm{K}_{\mathrm{f}}$ diinterpolasi dai nol di permukaan tanah sampai 2,5 di kedalaman 8d. Lebih bawah dari kedalaman ini, nilai $\mathrm{K}_{\mathrm{f}}$ berkurang dari 2,5 sampai 0,891 pada kedalaman 20d, atau, dianggap saja secara keseluruhan $\mathrm{K}_{\mathrm{f}}=0,9$.

Metode yang lain, untuk tiang dalam tanah pasir (tidak berlaku untuk lempung), gesek satuan dapat ditentukan dari tahanan konus $\mathrm{q}_{\mathrm{c}}$ :

$$
\mathrm{f}_{\mathrm{s}}=\mathrm{K}_{\mathrm{c}} \mathrm{q}_{\mathrm{c}}\left(\mathrm{kg} / \mathrm{cm}^{2}\right)
$$

Keterangan :

$\mathrm{f}_{\mathrm{s}}=\begin{aligned} & \text { Tahanan gesek satuan }\left(\mathrm{kg} / \mathrm{cm}^{2}\right) \text {, nilainya dibatasi sampai } 1,2 \mathrm{~kg} / \mathrm{cm}^{2} \\ & (120 \mathrm{kPa})\end{aligned}$

$\mathrm{q}_{\mathrm{c}}=$ Tahanan konus $\left(\mathrm{kg} / \mathrm{cm}^{2}\right)$

$\mathrm{K}_{\mathrm{c}}=$ Koefisien tak berdimensi yang nilainya bergantung pada tipe tiang

Tiang baja ujung bawah terbuka,

$\mathrm{K}_{\mathrm{c}}=0,8 \%$

Tiang pipa ujung bawah tertutup,

$\mathrm{K}_{\mathrm{c}}=1,8 \%$

Tiang beton,

$\mathrm{K}_{\mathrm{c}}=1,2 \%$

c. Metode Meyerhoff

1). Tahanan ujung

$$
\mathrm{f}_{\mathrm{b}}=\omega_{1} \omega_{2} \mathrm{q}_{\mathrm{ca}}
$$

Keterangan :

$\mathrm{f}_{\mathrm{b}}=$ Tahanan ujung satuan, untuk tiang bor diambil $70 \%$ atau 50\%-nya

$\mathrm{q}_{\mathrm{ca}}=\underset{\substack{\mathrm{c} \\ \text { atasnya }}}{\mathrm{q}_{\mathrm{ata}} \text { rata }\left(\mathrm{kN} / \mathrm{m}^{2}\right) \text { pada zona } 1 \mathrm{~d} \text { di bawah ujung tiang dan } 4 \mathrm{~d} \text { di }}$ 


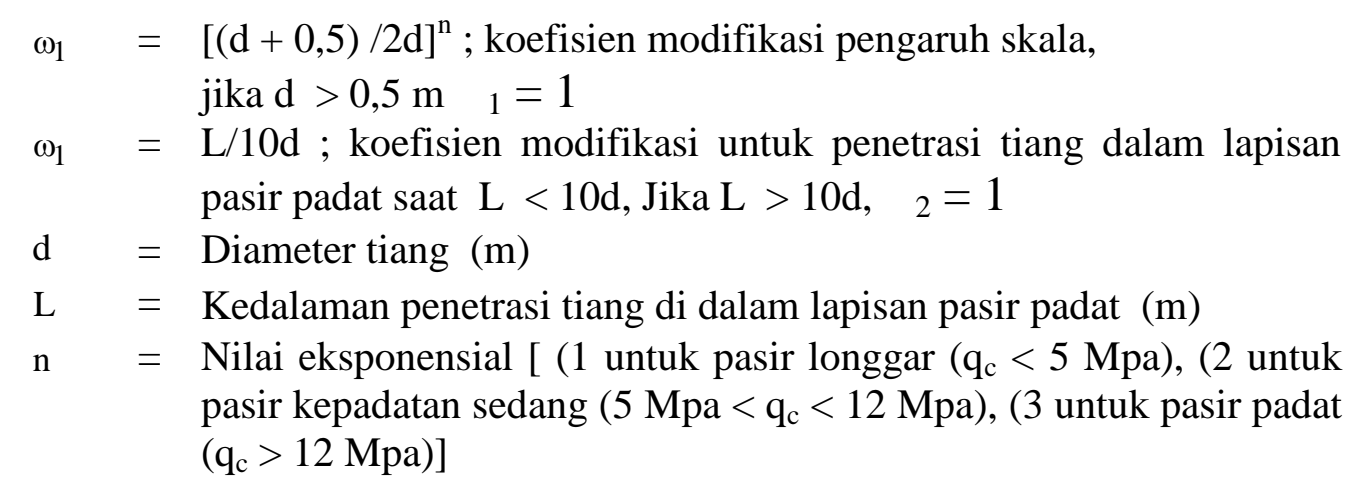

2). Tahanan gesek

Untuk tiang pancang, tahanan gesek satuan diambil salah satu dari :

$$
\mathrm{f}_{\mathrm{S}}=\mathrm{K}_{\mathrm{f}} \mathrm{q}_{\mathrm{f}} \quad \text { dengan } \mathrm{K}_{\mathrm{f}}=1
$$

atau, bila tidak dilakukan pengukuran tahanan gesek sisi konus :

$$
\mathrm{f}_{\mathrm{s}}=\mathrm{K}_{\mathrm{c}} \mathrm{q}_{\mathrm{c}} \quad \text { dengan } \mathrm{K}_{\mathrm{c}}=0,005
$$

Keterangan :

$\mathrm{f}_{\mathrm{S}} \quad=$ Tahanan gesek satuan $\left(\mathrm{kg} / \mathrm{cm}^{2}\right)$

$\mathrm{K}_{\mathrm{f}} \quad=$ Koefisien modifikasi tahanan gesek sisi konus

$\mathrm{K}_{\mathrm{f}}=$ Koefisien modifikasi tahanan konus

Untuk tiang bor, Meyerhoff menyarankan menggunakan faktor reduksi $70 \%$ dan $50 \%$ dalam menghitung tahanan gesek tiang dengan menggunakan persamaan (11) dan (12).

\section{Kapasitas Kuat Dukung Bored Pile Dari Hasil Standard Penetration Test $(N-$ SPT)}

a. Metode O'Neil dan Reese (1989)

1). Tahanan ujung ultimit

$$
\mathrm{Q}_{\mathrm{b}}=\mathrm{A}_{\mathrm{b}} \mathrm{f}_{\mathrm{b}}
$$

O’Neil dan Reese (1989) dari merekomendasikan tahanan ujung tiang bor pada penurunan $5 \%$ dari diameter dasar tiang pada pasir :

$$
\mathrm{f}_{\mathrm{b}}=0,60 \sigma_{\mathrm{r}} \mathrm{N}_{60} \leq 4500 \mathrm{kPa}
$$

Keterangan :

$\mathrm{A}_{\mathrm{b}}=$ Luas dasar tiang bor $\left(\mathrm{m}^{2}\right)$

$\mathrm{f}_{\mathrm{b}} \quad=$ Tahanan ujung neto per satuan luas $(\mathrm{kPa})$

$\mathrm{N}_{60}=$ Nilai $N$-SPT rata-rata antara ujung bawah tiang bor sampai $2 \mathrm{~d}_{\mathrm{b}} \mathrm{di}$ bawahnya, tidak perlu dikoreksi terhadap overburden

$\mathrm{d}_{\mathrm{b}}=$ Diameter ujung bawah tiang bor $(\mathrm{m})$

$\sigma_{\mathrm{r}} \quad=$ Tegangan referensi $=100 \mathrm{kPa}$ 
Jika tiang bor dasarnya berdiameter lebih dari $120 \mathrm{~cm}$, maka besarnya $\mathrm{f}_{\mathrm{b}}$ dapat mengakibatkan penurunan lebih besar dari $25 \mathrm{~mm}$ (1 inci). Untuk memenuhi syarat penurunan ijin, O'Neil dan Reese (1989) menyarankan $f_{b}$ direduksi menjadi $\mathrm{f}_{\text {br }}$ dengan :

$$
\mathrm{f}_{\mathrm{br}}=4,17\left(\mathrm{~d}_{\mathrm{r}} / \mathrm{d}_{\mathrm{b}}\right) \mathrm{f}_{\mathrm{b}} \text { bila }_{\mathrm{b}} \geq 1200 \mathrm{~mm}
$$

Keterangan :

$\mathrm{d}_{\mathrm{r}} \quad=$ Lebar referensi $=300 \mathrm{~mm}$

$\mathrm{d}_{\mathrm{b}}=$ Lebar ujung bawah tiang bor

Nilai tahanan ujung satuan yang dipakai dalam perancangan adalah $\mathrm{f}_{\mathrm{br}}$. Sebagai alternatif, O'Neil dan Reese (1989) menyarankan untuk melakukan analisis penurunan, kemudian merubah perancangan tiang sedemikian hingga penurunannya masih dalam batas-batas toleransi. Jika penurunan toleransi dibolehkan lebih besar atau lebih kecil dari $25 \mathrm{~mm}$, dan diameter tiang dimana penurunan berlebihan menjadi masalah, maka cara-cara penyesuaian dalam analisis hitungan $\mathrm{f}_{\mathrm{b}}$ perlu dilakukan.

2). Tahanan gesek ultimit

$$
\begin{aligned}
\mathrm{f}_{\mathrm{s}} & =\beta \sigma_{\mathrm{r}}{ }^{\prime} \\
\beta & =\mathrm{K} \tan \delta
\end{aligned}
$$

Keterangan :

$$
\begin{aligned}
& \mathrm{f}_{\mathrm{s}}=\text { Tahanan gesek satuan }\left(\mathrm{kN} / \mathrm{m}^{2}\right) \\
& \sigma_{\mathrm{r}}{ }^{\prime}=\text { Tekanan overbuden di tengah-tengah lapisan tanah }\left(\mathrm{kN} / \mathrm{m}^{2}\right) \\
& \delta
\end{aligned}
$$

Metode ini disebut juga dengan metode $\beta$. Nilai $\mathrm{K} / \mathrm{K}_{\mathrm{o}}$ ditunjukkan dalam tabel 3 dan rasio $\delta / \varphi$ ' ditunjukkan dalam tabel 4 . Koefisien $\beta$ juga dapat dihitung dengan menggunakan persamaan yang disarankan oleh O'Neil dan Reese (1989):

$$
\begin{aligned}
& \beta=1,5-0,135 \sqrt{\mathrm{z} / \mathrm{dr}} \\
& \text { dengan } 0,25 \leq \beta \leq 1,2
\end{aligned}
$$

\begin{tabular}{|c|c|}
\hline Metode Pelaksanaan & $\mathrm{K} / \mathrm{K}_{\mathrm{o}}$ \\
\hline $\begin{array}{l}\text { Pelaksanaan kering dengan gangguan dinding } \\
\text { lubang bor kecil, pengecoran cepat }\end{array}$ & 1 \\
\hline Pelaksanaan dengan cairan - cara kerja baik & 1 \\
\hline Pelaksanaan dengan cairan - cara kerja buruk & 0,67 \\
\hline Dengan pipa selubung di bawah air & 0,83 \\
\hline
\end{tabular}

Keterangan :

$\mathrm{d}_{\mathrm{r}} \quad=$ Lebar referensi $=300 \mathrm{~mm}$

$\mathrm{z} \quad=$ Kedalaman di tengah-tengah lapisan tanah $(\mathrm{m})$

Tabel 3. Nilai-nilai $\mathrm{K} / \mathrm{K}_{\mathrm{o}}$ untuk tiang bor

(Sumber : Kulhawy, 1991) 
Tabel 4. Nilai-nilai $\delta / \varphi$ ' untuk tiang bor

\begin{tabular}{lc}
\hline \multicolumn{1}{c}{ Metode Pelaksanaan } & $\delta / \varphi$ \\
\hline $\begin{array}{l}\text { Lubang terbuka atau dengan pipa selubung sementara } \\
\text { Metode dengan cairan (slurry method) - minimum }\end{array}$ & 1 \\
slurry cake & 1 \\
Metode dengan cairan (slurry method) - maksimal & 0,8 \\
slurry cake & 0,7 \\
Pipa selubung permanen &
\end{tabular}

Bila lebar referensi $\mathrm{dr}=300 \mathrm{~mm}$ disubstitusikan ke persamaan (18)

$$
\begin{gathered}
\beta=1,5-0,245 \sqrt{\mathrm{z}} \\
\text { dengan } 0,25 \leq \beta \leq 1,2
\end{gathered}
$$

Jika $N_{60} \leq 15$, maka $\beta$ dalam persamaan (19) dikalikan dengan $N_{60} / 15$ atau

$$
\begin{aligned}
& \beta=\mathrm{N}_{60} / 15(1,5-0,245 \sqrt{\mathrm{z}}) \\
& \text { untuk } N_{60} \leq 15
\end{aligned}
$$

$N_{60}$ adalah $N$-SPT yang tidak dikoreksi terhadap overburden dan hanya dikoreksi oleh prosedur (alat) di lapangan.

Beberapa nilai $\beta$ untuk tanah non-kohesif yang disarankan oleh Reese dkk (2006) :

(1). Untuk pasir:

$$
\beta=0,25 \text {, jika } \mathrm{z}>26,14 \mathrm{~m}
$$

(2). Untuk pasir yang banyak mengandung kerikil:

$$
\beta=2-0,15(\mathrm{z})^{0,75} \text { dengan } 0,25 \leq \beta \leq 1,8
$$

(3). Untuk pasir berkerikil atau kerikil:

$$
\beta=0,25 \text {, jika } \mathrm{z}>26,5 \mathrm{~m}
$$

Untuk pasir dan pasir berkerikil, fungsi $\beta$ mencapai batasnya pada kedalaman $\mathrm{z}=$ $1,5 \mathrm{~m}$ dan $26 \mathrm{~m}$, karena itu pembuatan batas-batas lapisan tanah harus dalam zonazona diantaranya. Selain itu, batas lapisan juga harus dibuat pada permukaan air tanah. Batas-batas tambahan juga harus dibuat pada setiap interval $6 \mathrm{~m}$, dan dimana batas dari lapisan pasir berakhir. Setelah itu, analisis didasarkan pada macam tanahnya (lempung atau pasir).

b. Metode Meyerhoff (1976)

1). Kuat dukung ujung

$$
\mathrm{Q}_{\mathrm{b}}=\mathrm{A}_{\mathrm{b}} \mathrm{q}_{\mathrm{b}}
$$

Keterangan :

$\mathrm{A}_{\mathrm{b}} \quad=$ Luas penampang bored pile $\left(\mathrm{m}^{2}\right)$

$\mathrm{q}_{\mathrm{b}}=$ Tahanan ujung per satuan luas $\left(\mathrm{kN} / \mathrm{m}^{2}\right)$

$\mathrm{Q}_{\mathrm{b}} \quad=$ Kuat dukung ujung tiang $(\mathrm{kN})$ 
2). Tahanan ujung

$$
\mathrm{q}_{\mathrm{b}}=\sigma_{\mathrm{r}}{ }^{\prime} \mathrm{N}_{\mathrm{q}} * \leq 50 \mathrm{~N}_{\mathrm{q}} * \tan \Phi
$$

Keterangan :

$\mathrm{q}_{\mathrm{b}}=$ Tahanan ujung per satuan luas $\left(\mathrm{kN} / \mathrm{m}^{2}\right)$

$\sigma_{\mathrm{r}}{ }^{\prime}=$ Tegangan efektif (overburden) $\left(\mathrm{kN} / \mathrm{m}^{2}\right)$

$\mathrm{N}_{\mathrm{q}} *=$ Faktor kuat dukung

$\Phi=$ Sudut geser dalam tanah

3). Kuat dukung selimut

$$
\mathrm{Q}_{\mathrm{S}}=\sum \mathrm{A}_{\mathrm{S}} \mathrm{q}_{\mathrm{s}}
$$

Dengan

$$
\mathrm{A}_{\mathrm{S}}=\Theta_{\mathrm{i}} \cdot \mathrm{L}_{\mathrm{i}}
$$

Keterangan :

$\mathrm{A}_{\mathrm{s}} \quad=$ Luas selimut tiang $\left(\mathrm{m}^{2}\right)$

$\mathrm{q}_{\mathrm{s}} \quad=$ Nilai tahanan sisi tiang sepanjang $\mathrm{L}_{\mathrm{i}}$ dengan tanah setebal $\mathrm{L}_{\mathrm{i}}$ adalah tahanan sisi persatuan luas sisi tiang $\left(\mathrm{kN} / \mathrm{m}^{2}\right)$

$\Theta_{\mathrm{i}} \quad=$ Keliling tiang pada selang $\mathrm{L}_{\mathrm{i}}(\mathrm{m})$

$\mathrm{L}_{\mathrm{i}} \quad=$ Panjang bagian tiang dengan keliling $\Theta_{\mathrm{i}}(\mathrm{m})$

4). Tahanan sisi tiang

$$
\mathrm{q}_{\mathrm{s}}=\mathrm{K} \sigma_{\mathrm{r}}{ }^{\prime} \tan \delta
$$

Keterangan :

$\mathrm{K}=$ Koefisien tekanan tanah lateral pada sisi tiang yang ditinjau

$\sigma_{\mathrm{r}}{ }^{\prime}=$ Tegangan efektif (overburden) $\left(\mathrm{kN} / \mathrm{m}^{2}\right)$

\begin{tabular}{|c|c|c|}
\hline \multirow{2}{*}{ Jenis Konstruksi } & \multicolumn{2}{|c|}{ Parameter tahanan sisi } \\
\hline & Batas bawah & Batas atas \\
\hline Tiang bor (bored pile) & \multicolumn{2}{|c|}{$\mathrm{K}=1-\sin \Phi$} \\
\hline Low displacement driven piles & $\mathrm{K}=1-\sin \Phi$ & $\mathrm{K}=1.4(1-\sin \Phi)$ \\
\hline Low displacement driven piles, Meyerhoff (1976) & - & $\mathrm{q}_{\mathrm{s}}=\mathrm{N}_{\mathrm{spt}}\left(\mathrm{kN} / \mathrm{m}^{2}\right)$ \\
\hline High displacement driven piles & $\mathrm{K}=1-\sin \Phi$ & $\mathrm{K}=1.8(1-\sin \Phi)$ \\
\hline High displacement driven piles, Bhusan (1982) & \multicolumn{2}{|c|}{$\begin{array}{l}\mathrm{K}=0,5+0,008 \mathrm{Dr} \\
\mathrm{Dr}=\text { Kerapatan relatif }(\%)\end{array}$} \\
\hline High displacement driven piles, Meyerhoff (1976) & - & $\mathrm{q}_{\mathrm{s}}=2 \mathrm{~N}_{\mathrm{spt}}\left(\mathrm{kN} / \mathrm{m}^{2}\right)$ \\
\hline
\end{tabular}

$\delta=$ Sudut geser antara tiang dengan tanah dengan nilai $1 / 2 \Phi$ hingga $\Phi$

$\Phi=$ Sudut geser dalam tanah

Tabel 5. Pemilihan parameter tahanan sisi 
c. Metode Coyle dan Castello ( 1981)

1). Kuat dukung ujung

$$
\mathrm{Q}_{\mathrm{b}}=\mathrm{A}_{\mathrm{b}} \cdot \sigma_{\mathrm{r}}{ }^{\prime} \cdot \mathrm{N}_{\mathrm{q}} *
$$

Keterangan :

$\mathrm{A}_{\mathrm{b}} \quad=$ Luas penampang bored pile $\left(\mathrm{m}^{2}\right)$

$\sigma_{\mathrm{r}}{ }^{\prime} \quad=$ Tegangan vertikal efektif pada ujung tiang $\left(\mathrm{kN} / \mathrm{m}^{2}\right)$

$\mathrm{N}_{\mathrm{q}} *=$ Faktor kuat dukung

2). Kuat dukung selimut

$$
\begin{aligned}
& \mathrm{Q}_{\mathrm{S}}=\mathrm{f}_{\mathrm{av}} \cdot \mathrm{S} \cdot \mathrm{L} \\
& \mathrm{f}_{\mathrm{av}}=\mathrm{K} \sigma_{\mathrm{r}}{ }^{\prime} \tan \delta
\end{aligned}
$$

Keterangan :

$\mathrm{f}_{\mathrm{av}}=$ Tahanan gesek rata-rata untuk keseluruhan tiang $\left(\mathrm{kN} / \mathrm{m}^{2}\right)$

$\mathrm{K}=$ Koefisien tekanan tanah lateral

$\sigma_{\mathrm{r}}{ }^{\prime}=$ Tekanan overburden efektif rata-rata $\left(\mathrm{kN} / \mathrm{m}^{2}\right)$

$\delta=$ Sudut gesek antara tiang dan tanah

Berdasarkan studi ini, perhitungan untuk nilai faktor kuat dukung $\left(\mathrm{N}_{\mathrm{q}}{ }^{*}\right)$ dikorelasikan dengan nisbah panjang tiang L/D. Gambar 1 memperlihatkan nilai-nilai $\mathrm{N}_{\mathrm{q}}{ }^{*}$ untuk berbagai nisbah panjang tiang dan sudut gesek tanah. Di sini $\mathrm{N}_{\mathrm{q}} *$ secara perlahan akan meningkat dengan L/D hingga mencapai suatu nilai maksimum tertentu dan akan menurun sesudahnya.

Earth pressure coefficient. K

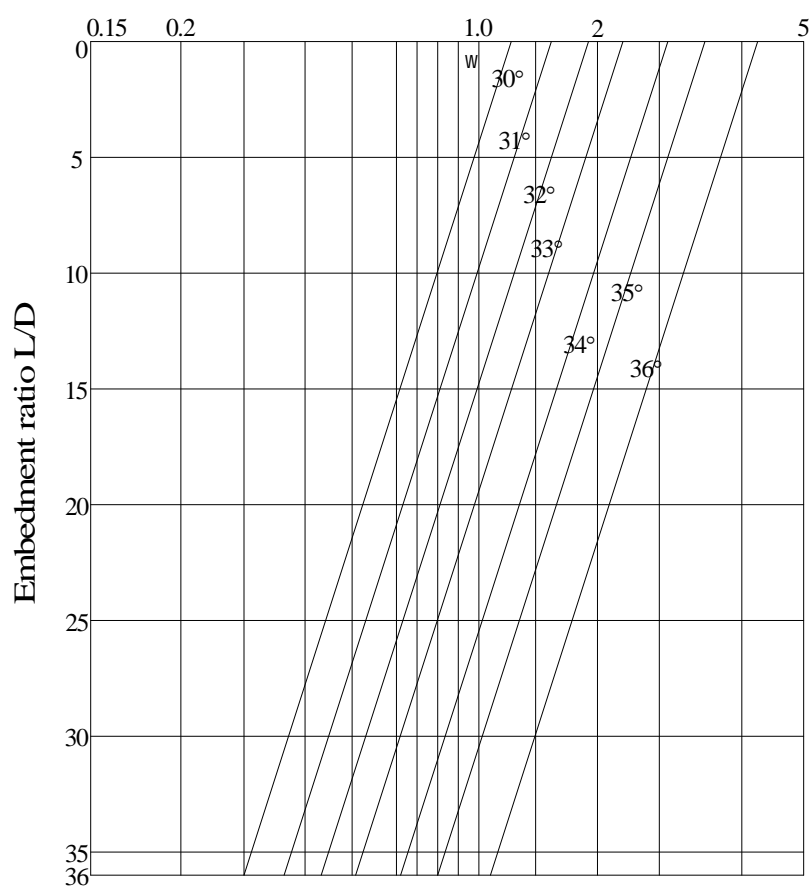

Gambar 1. Variasi $\mathrm{N}_{\mathrm{q}} *$ dengan L/D (Coyle dan Castello, 1981)

(Sumber : Bowles, 1996) 
Dengan cara yang sama, nilai-nilai deduksi $\mathrm{K}$ untuk berbagai nilai $\Phi$ dan nisbah L/D diberikan pada gambar 2 Di sini dapat terlihat bahwa untuk setiap nilai $\Phi, \mathrm{K}$ berkurang secara linier dengan nisbah L/D.

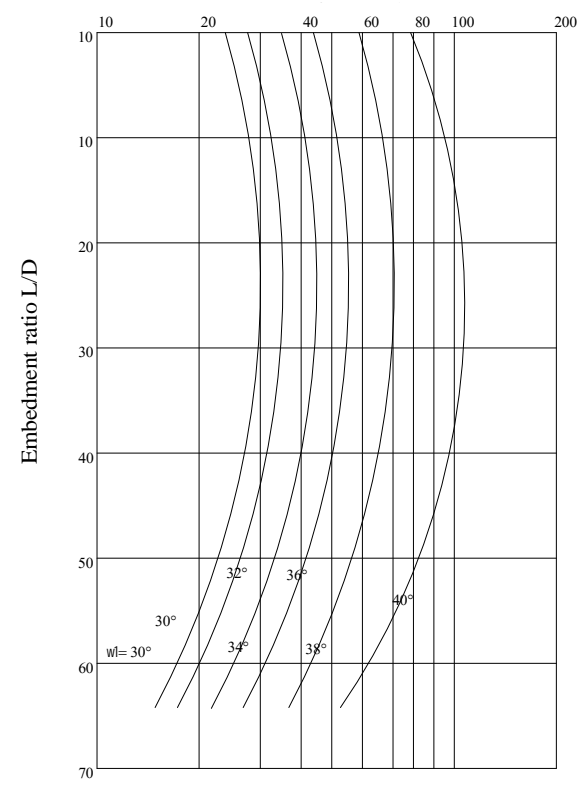

Gambar 2. Variasi K dengan L/D (Coyle dan Castello, 1981)

(Sumber : Bowles, 1996)

\section{DATA DAN ANALISIS DATA}

\section{Data Perencanaan Teknis Bored Pile}

Data teknis bored pile yang akan diuji didalam perhitungan :
a. Panjang Bored pile : $20 \mathrm{~m}$
b. Diameter Bored pile : $\varnothing(40,60 \& 80) \mathrm{cm}$
c. Jumlah titik : Titik Sondir S3
d. Mutu Beton : K-350

\section{Metode Pengumpulan Data}

Untuk perolehan data pada perhitungan perencanaan pondasi bored pile pada proyek pembangunan gedung dan perbengkelan 7 lantai ini diperoleh dari pelaksana penyelidikan tanah (sondir dan standar penetrasi test).

a. Cara Analisis

Dalam perencanaan pondasi bored pile ada beberapa langkah yang akan dilakukan, diantaranya :

1). Menghitung kapasitas kuat dukung bored pile.

2). Membandingkan hasil perhitungan kuat dukung pondasi bored pile dari berberapa metode diantaranya :

a). Dari data sondir dengan metode Meyerhoff dan metode Schmertmann dan Nottingham.

b). Dari data standard penetration test dengan metode O'Neil dan Reese, metode Mayerhoff dan metode Coyle dan Castello. 
b. Lokasi Titik Sondir

Sondir yang dilaksanakan pada proyek pembangunan gedung dan perbengkelan 7 (tujuh) lantai terdiri dari 5 (lima) titik.

D. HASIL DAN PEMBAHASAN

1. Menghitung Kapasitas Kuat Dukung Bored Pile dari Data Sondir

CPT-Test

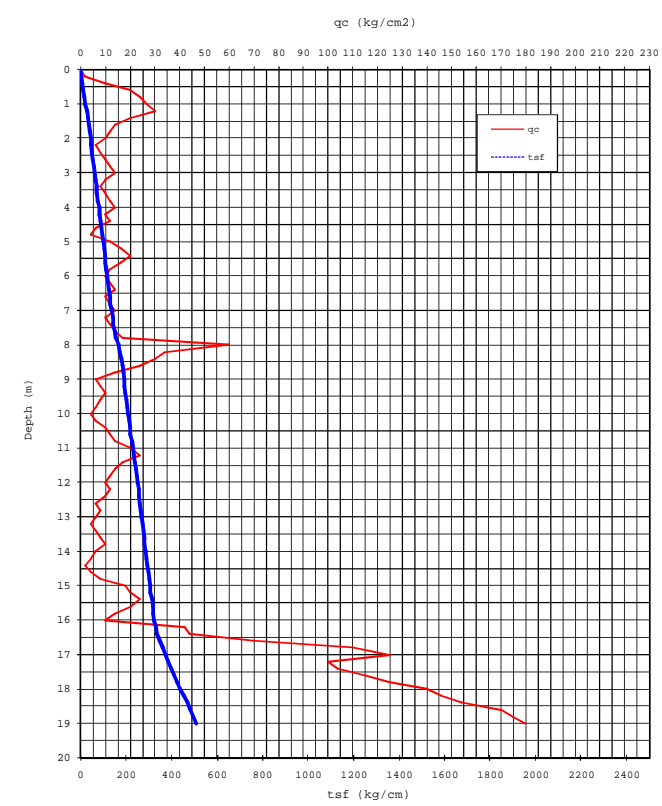

Gambar 3. $C P T-$ Test untuk titik sondir S-3

a. Metode Schertmann dan Nottingham

1). Diameter tiang bored pile $40 \mathrm{~cm}$

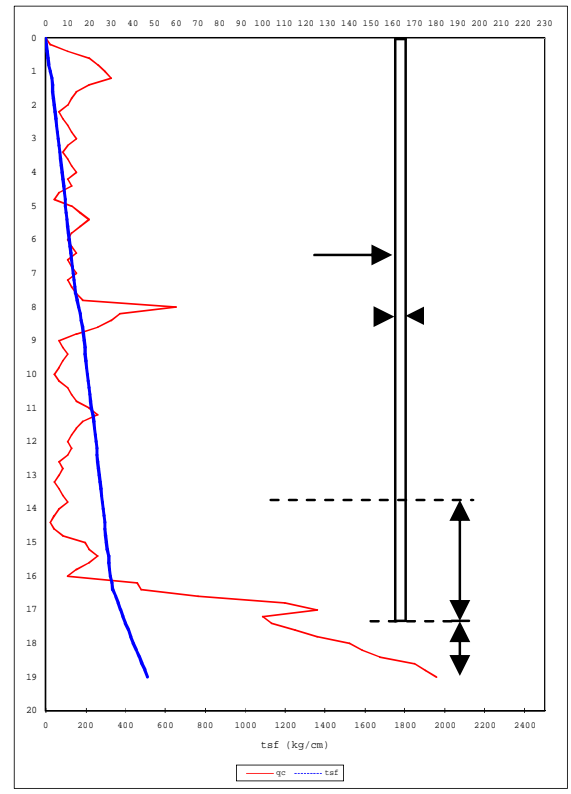

Gambar 4. Cara menghitung tahanan ujung dari uji kerucut statis metode Schmertmann dan Nottingham (1975), diameter tiang $40 \mathrm{~cm}$ 
Data sondir yang dipakai untuk perhitungan kuat dukung adalah titik S-3. Tahanan ujung tiang persatuan luas $\left(\mathrm{f}_{\mathrm{b}}\right)=$ nilai rata-rata $\mathrm{q}_{\mathrm{c}}$ sepanjang $8 \mathrm{~d}$ di atas dasar tiang dan $4 \mathrm{~d}$ di bawah tiang

a). Tahanan ujung persatuan luas $\left(\mathrm{f}_{\mathrm{b}}\right)$

$$
\begin{aligned}
& \mathrm{Q}_{\mathrm{u}}=\mathrm{A}_{\mathrm{b}} \cdot \mathrm{f}_{\mathrm{b}}+\mathrm{A}_{\mathrm{s}} \cdot \mathrm{f}_{\mathrm{s}} \\
& \text { atau } \\
& \mathrm{Q}_{\mathrm{u}}=\mathrm{A}_{\mathrm{b}} \cdot \omega \cdot \mathrm{q}_{\mathrm{ca}}+\mathrm{A}_{\mathrm{s}} \cdot \mathrm{K}_{\mathrm{f}} \cdot \mathrm{q}_{\mathrm{f}} \\
& \mathrm{q}_{\mathrm{c} 1}=\frac{(4+6+10+20+22+27+22+16+12+46+47+77+117+132+107+110)}{16} \\
& \mathrm{q}_{\mathrm{c} 1}=48,44 \mathrm{~kg} / \mathrm{cm}^{2} \\
& \mathrm{q}_{\mathrm{c} 2}=\frac{(123+132+147+154+164+177+183+187)}{8} \\
& \mathrm{q}_{\mathrm{c} 2}=158,38 \mathrm{~kg} / \mathrm{cm}^{2} \\
& \mathrm{q}_{\mathrm{ca}}=1 / 2\left(\mathrm{q}_{\mathrm{c} 1}+\mathrm{q}_{\mathrm{c} 2}\right) \\
& =1 / 2(48,44+158,38) \mathrm{kg} / \mathrm{cm}^{2} \\
& =103,41 \mathrm{~kg} / \mathrm{cm}^{2} \\
& =10341 \mathrm{KN} / \mathrm{m}^{2} \\
& \mathrm{f}_{\mathrm{b}}=\omega \cdot \mathrm{q}_{\mathrm{ca}} \leq 150 \mathrm{~kg} / \mathrm{cm}^{2}\left(15000 \mathrm{KN} / \mathrm{m}^{2}\right)
\end{aligned}
$$

Asumsi pasir terkonsolidasi normal $(\mathrm{OCR}=1)$, nilai faktor $\omega=1$

$\mathrm{f}_{\mathrm{b}}=1 \times 103,41 \mathrm{~kg} / \mathrm{cm}^{2}=103,41 \mathrm{~kg} / \mathrm{cm}^{2}=10341 \mathrm{KN} / \mathrm{m}^{2} \leq 15000 \mathrm{KN} / \mathrm{m}^{2}$

b). Tahanan ujung

$$
\begin{aligned}
\mathrm{Q}_{\mathrm{b}} & =A_{\mathrm{b}} \cdot \mathrm{f}_{\mathrm{b}} \\
& =1 / 4 \pi(40)^{2} \times 103,41 \mathrm{~kg} / \mathrm{cm}^{2} \\
& =1256 \mathrm{~cm}^{2} \times 103,41 \mathrm{~kg} / \mathrm{cm}^{2} \\
& =129882,96 \mathrm{~kg} \\
& =1298,83 \mathrm{KN}
\end{aligned}
$$

c). Tahanan gesek

$\mathrm{Q}_{\mathrm{s}}=\mathrm{A}_{\mathrm{s}} \cdot \mathrm{f}_{\mathrm{s}}$

$\mathrm{A}_{\mathrm{s}}=\pi \cdot \mathrm{d} . \mathrm{L} \quad($ dimana $\mathrm{L}=17,40 \mathrm{~m})$

$=\pi \cdot(0,4) \cdot 17,40$

$=21,85 \mathrm{~m}^{2}$

$\mathrm{f}_{\mathrm{s}}=\mathrm{k}_{\mathrm{f}} \cdot \mathrm{q}_{\mathrm{f}}$

nilai $\mathrm{k}_{\mathrm{f}}=0,9$

dan $\mathrm{q}_{\mathrm{f}}=$ diambil rata-rata tabel sondir $=0,37$

$\mathrm{f}_{\mathrm{s}}=0,9 \times 0,37 \mathrm{~kg} / \mathrm{cm}^{2}$

$=0,333 \mathrm{~kg} / \mathrm{cm}^{2}$

$=33,3 \mathrm{KN} / \mathrm{m}^{2}$

$\mathrm{Q}_{\mathrm{s}}=\mathrm{A}_{\mathrm{s}} \cdot \mathrm{f}_{\mathrm{s}}$

$=21,85 \mathrm{~m}^{2} \times 33,3 \mathrm{KN} / \mathrm{m}^{2}$

$=727,61 \mathrm{KN}$

d). Kuat dukung ultimit

$$
\begin{aligned}
\mathrm{Q}_{\mathrm{u}} & =\mathrm{Q}_{\mathrm{b}}+\mathrm{Q}_{\mathrm{s}} \\
& =(1298,83+727,61) \mathrm{KN} \\
& =2026,44 \mathrm{KN}
\end{aligned}
$$


2). Diameter tiang bored pile $60 \mathrm{~cm}$

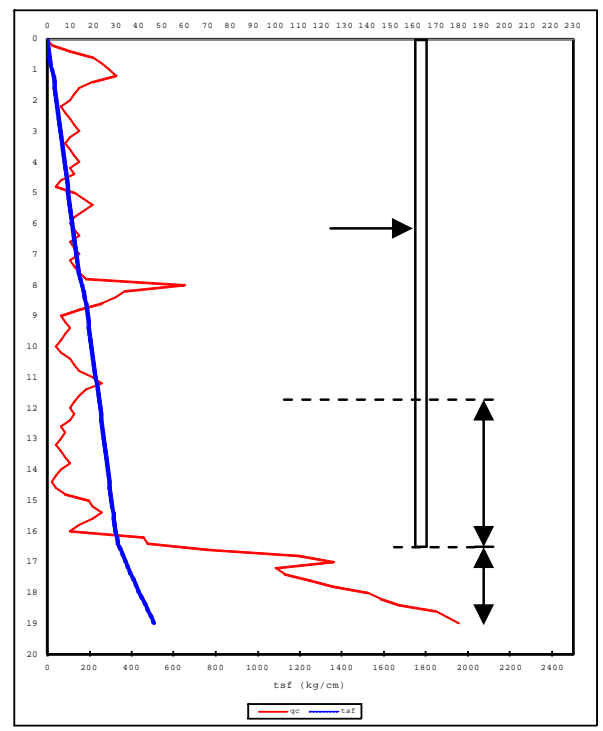

Gambar 5. Cara menghitung tahanan ujung dari uji kerucut statis metode Schmertmann dan Nottingham (1975), diameter tiang $60 \mathrm{~cm}$

a). Tahanan ujung persatuan luas $\left(\mathrm{f}_{\mathrm{b}}\right)$

$$
\begin{aligned}
& \mathrm{Q}_{\mathrm{u}}=\mathrm{A}_{\mathrm{b}} \cdot \mathrm{f}_{\mathrm{b}}+\mathrm{A}_{\mathrm{s}} \cdot \mathrm{f}_{\mathrm{s}} \\
& \text { atau } \\
& \mathrm{Q}_{\mathrm{u}}=\mathrm{A}_{\mathrm{b}} \cdot \omega \cdot \mathrm{q}_{\mathrm{ca}}+\mathrm{A}_{\mathrm{s}} \cdot \mathrm{K}_{\mathrm{f}} \cdot \mathrm{q}_{\mathrm{f}} \\
& \mathrm{q}_{\mathrm{c} 1}=\frac{(12+14+12+8+10+8+6+8+10+12+8+6+4+6+10+20+22+27+22+16)}{24} \\
& \mathrm{q}_{\mathrm{c} 1}=17,63 \mathrm{~kg} / \mathrm{cm}^{2} \\
& \mathrm{q}_{\mathrm{c} 2}=\frac{(117+132+107+110+123+132+147+154+164+177+183+187)}{12} \\
& \mathrm{q}_{\mathrm{c} 2}=144,42 \mathrm{~kg} / \mathrm{cm}^{2} \\
& \mathrm{q}_{\mathrm{ca}}=1 / 2\left(\mathrm{q}_{\mathrm{c} 1}+\mathrm{q}_{\mathrm{c} 2}\right) \\
& =1 / 2(17,63+144,42) \mathrm{kg} / \mathrm{cm}^{2} \\
& =81,03 \mathrm{~kg} / \mathrm{cm}^{2} \\
& =8103 \mathrm{KN} / \mathrm{m}^{2} \\
& \mathrm{f}_{\mathrm{b}}=\omega \cdot \mathrm{q}_{\mathrm{ca}} \leq 150 \mathrm{~kg} / \mathrm{cm}^{2}\left(15000 \mathrm{KN} / \mathrm{m}^{2}\right)
\end{aligned}
$$

Asumsi pasir terkonsolidasi normal $(\mathrm{OCR}=1)$, nilai faktor $\omega=1$ $\mathrm{f}_{\mathrm{b}}=1 \times 81,03 \mathrm{~kg} / \mathrm{cm}^{2}=81,03 \mathrm{~kg} / \mathrm{cm}^{2}=8103 \mathrm{KN} / \mathrm{m}^{2} \leq 15000 \mathrm{KN} / \mathrm{m}^{2}$

b). Tahanan ujung

$$
\begin{aligned}
\mathrm{Q}_{\mathrm{b}} & =A_{\mathrm{b}} \cdot \mathrm{f}_{\mathrm{b}} \\
& =1 / 4 \pi(60)^{2} \times 81,03 \mathrm{~kg} / \mathrm{cm}^{2} \\
& =2826 \mathrm{~cm}^{2} \times 81,03 \mathrm{~kg} / \mathrm{cm}^{2} \\
& =228990,78 \mathrm{~kg} \\
& =2289,91 \mathrm{KN}
\end{aligned}
$$


c). Tahanan gesek

$$
\begin{aligned}
& \mathrm{Q}_{\mathrm{s}}=\mathrm{A}_{\mathrm{s}} \cdot \mathrm{f}_{\mathrm{s}} \\
& \mathrm{A}_{\mathrm{s}}=\pi \cdot \mathrm{d} \cdot \mathrm{L} \quad(\text { dimana } \mathrm{L}=16,60 \mathrm{~m}) \\
&=\pi \cdot(0,6) \cdot 16,60 \\
&=31,27 \mathrm{~m}^{2} \\
& \mathrm{f}_{\mathrm{s}}=\mathrm{k}_{\mathrm{f}} \cdot \mathrm{q}_{\mathrm{f}} \\
& \text { nilai } \mathrm{k}_{\mathrm{f}}=0,9 \\
& \text { dan } \mathrm{q}_{\mathrm{f}}=\text { diambil rata-rata tabel sondir }=0,37 \\
& \begin{aligned}
\mathrm{f}_{\mathrm{s}} & =0,9 \times 0,37 \mathrm{~kg} / \mathrm{cm}^{2} \\
& =0,333 \mathrm{~kg} / \mathrm{cm}^{2} \\
& =33,3 \mathrm{KN} / \mathrm{m}^{2} \\
\mathrm{Q}_{\mathrm{s}} & =\mathrm{A}_{\mathrm{s}} \cdot \mathrm{f}_{\mathrm{s}} \\
& =31,27 \mathrm{~m}^{2} \times 33,3 \mathrm{KN} / \mathrm{m}^{2} \\
& =1041,29 \mathrm{KN}
\end{aligned}
\end{aligned}
$$

d). Kuat dukung ultimit

$$
\begin{aligned}
\mathrm{Q}_{\mathrm{u}} & =\mathrm{Q}_{\mathrm{b}}+\mathrm{Q}_{\mathrm{s}} \\
& =(2289,91+1041,29) \mathrm{KN} \\
& =3331,20 \mathrm{KN}
\end{aligned}
$$

3). Diameter tiang bored pile $80 \mathrm{~cm}$

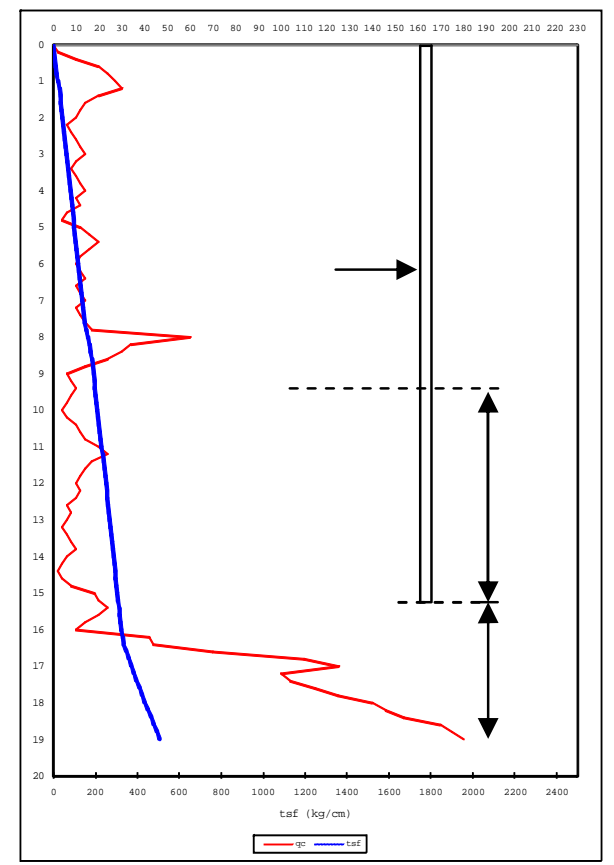

Gambar 6. Cara menghitung tahanan ujung dari uji kerucut statis metode Schmertmann dan Nottingham (1975), diameter tiang $80 \mathrm{~cm}$

a). Tahanan ujung persatuan luas $\left(\mathrm{f}_{\mathrm{b}}\right)$

$$
\begin{aligned}
\mathrm{Q}_{\mathrm{u}} & =\mathrm{A}_{\mathrm{b}} \cdot \mathrm{f}_{\mathrm{b}}+\mathrm{A}_{\mathrm{s}} \cdot \mathrm{f}_{\mathrm{s}} \\
\text { atau } & \\
\mathrm{Q}_{\mathrm{u}} & =\mathrm{A}_{\mathrm{b}} \cdot \omega \cdot \mathrm{q}_{\mathrm{ca}}+\mathrm{A}_{\mathrm{s}} \cdot \mathrm{K}_{\mathrm{f}} \cdot \mathrm{q}_{\mathrm{f}} \\
\mathrm{q}_{\mathrm{c} 1} & =12,97 \mathrm{~kg} / \mathrm{cm}^{2}
\end{aligned}
$$




$$
\begin{aligned}
\mathrm{q}_{\mathrm{c} 2} & =119,69 \mathrm{~kg} / \mathrm{cm}^{2} \\
\mathrm{q}_{\mathrm{ca}} & =1 / 2\left(\mathrm{q}_{\mathrm{c} 1}+\mathrm{q}_{\mathrm{c} 2}\right) \\
& =1 / 2(12,97+119,69) \mathrm{kg} / \mathrm{cm}^{2} \\
& =66,33 \mathrm{~kg} / \mathrm{cm}^{2} \\
& =6633 \mathrm{KN} / \mathrm{m}^{2} \\
\mathrm{f}_{\mathrm{b}} & =\omega \cdot \mathrm{q}_{\mathrm{ca}} \leq 150 \mathrm{~kg} / \mathrm{cm}^{2}\left(15000 \mathrm{KN} / \mathrm{m}^{2}\right)
\end{aligned}
$$

Asumsi pasir terkonsolidasi normal $(\mathrm{OCR}=1)$, nilai faktor $\omega=1$

$\mathrm{f}_{\mathrm{b}}=1 \times 66,33 \mathrm{~kg} / \mathrm{cm}^{2}=66,33 \mathrm{~kg} / \mathrm{cm}^{2}=6633 \mathrm{KN} / \mathrm{m}^{2} \leq 15000 \mathrm{KN} / \mathrm{m}^{2}$

b). Tahanan ujung

$$
\begin{aligned}
\mathrm{Q}_{\mathrm{b}} & =A_{\mathrm{b}} \cdot \mathrm{f}_{\mathrm{b}} \\
& =1 / 4 \pi(80)^{2} \times 66,33 \mathrm{~kg} / \mathrm{cm}^{2} \\
& =5024 \mathrm{~cm}^{2} \times 66,33 \mathrm{~kg} / \mathrm{cm}^{2} \\
& =333241,92 \mathrm{~kg} \\
& =3332,42 \mathrm{KN}
\end{aligned}
$$

c). Tahanan gesek

$$
\begin{aligned}
\mathrm{Q}_{\mathrm{s}} & =\mathrm{A}_{\mathrm{s}} \cdot \mathrm{f}_{\mathrm{s}} \\
\mathrm{A}_{\mathrm{s}} & =\pi \cdot \mathrm{d} \cdot \mathrm{L} \quad(\text { dimana } \mathrm{L}=15,80 \mathrm{~m}) \\
& =\pi \cdot(0,8) \cdot 15,80 \\
& =39,69 \mathrm{~m}^{2} \\
\mathrm{f}_{\mathrm{s}} & =\mathrm{k}_{\mathrm{f}} \cdot \mathrm{q}_{\mathrm{f}} \\
\text { nilai } & \mathrm{k}_{\mathrm{f}}=0,9 \\
\text { dan } & \mathrm{q}_{\mathrm{f}}=\text { diambil rata-rata tabel sondir }=0,37 \\
\mathrm{f}_{\mathrm{s}}=0,9 \times 0,37 \mathrm{~kg} / \mathrm{cm}^{2} & =0,333 \mathrm{~kg} / \mathrm{cm}^{2} \\
& =33,3 \mathrm{KN} / \mathrm{m}^{2} \\
\mathrm{Q}_{\mathrm{s}} & =\mathrm{A}_{\mathrm{s}} \cdot \mathrm{f}_{\mathrm{s}} \\
& =39,69 \mathrm{~m}^{2} \times 33,3 \mathrm{KN} / \mathrm{m}^{2} \\
& =1321,68 \mathrm{KN}
\end{aligned}
$$

d). Kuat dukung ultimit

$$
\begin{aligned}
\mathrm{Q}_{\mathrm{u}} & =\mathrm{Q}_{\mathrm{b}}+\mathrm{Q}_{\mathrm{s}} \\
& =(3332,42+1321,68) \mathrm{KN} \\
& =4654,10 \mathrm{KN}
\end{aligned}
$$

Tabel 6. Perhitungan kuat dukung bored pile dengan metode Schertmann dan Nottingham dari beberapa diameter tiang

\begin{tabular}{ccccc}
\hline No & $\begin{array}{c}\text { Diameter } \\
\text { Tiang }(d) \\
\text { cm }\end{array}$ & $\begin{array}{c}\text { Tahanan } \\
\text { Ujung }\left(Q_{b}\right) \\
\text { KN }\end{array}$ & $\begin{array}{c}\text { Tahanan } \\
\text { Gesek }\left(Q_{s}\right) \\
\text { KN }\end{array}$ & $\begin{array}{c}\text { Kuat Dukung } \\
\text { Ultimit }\left(Q_{u}\right) \\
\text { KN }\end{array}$ \\
\hline 1. & 40 & 1298,83 & 727,61 & 2026,44 \\
2. & 60 & 2289,91 & 1041,29 & 3331,20 \\
3. & 80 & 3332,42 & 1321,68 & 4654,10 \\
\hline
\end{tabular}


b. Metode Meyerhoff

1). Untuk tiang bor berdiameter $40 \mathrm{~cm}(0,4 \mathrm{~m})$

a). Tahanan ujung persatuan luas $\left(\mathrm{f}_{\mathrm{b}}\right)$

$f_{b}=\omega_{1} \cdot \omega_{2} \cdot q_{c a}$

Keterangan :

$\mathrm{f}_{\mathrm{b}}=$ tahanan ujung satuan, untuk tiang bor diambil $70 \%$ atau $50 \%$-nya

$\mathrm{q}_{\mathrm{ca}}=\frac{(107+110+123+132+147+154+164+177+183+187)}{10}$

$\mathrm{q}_{\mathrm{ca}}=148,40 \mathrm{~kg} / \mathrm{cm}^{2}=14691 \mathrm{KN} / \mathrm{m}^{2}$

Karena $\mathrm{d}=0,4 \mathrm{~m}<0,5 \mathrm{~m}$ dan $\mathrm{L}>10 \mathrm{~d}$, nilai $\omega_{1}$ dan $\omega_{2}=1$

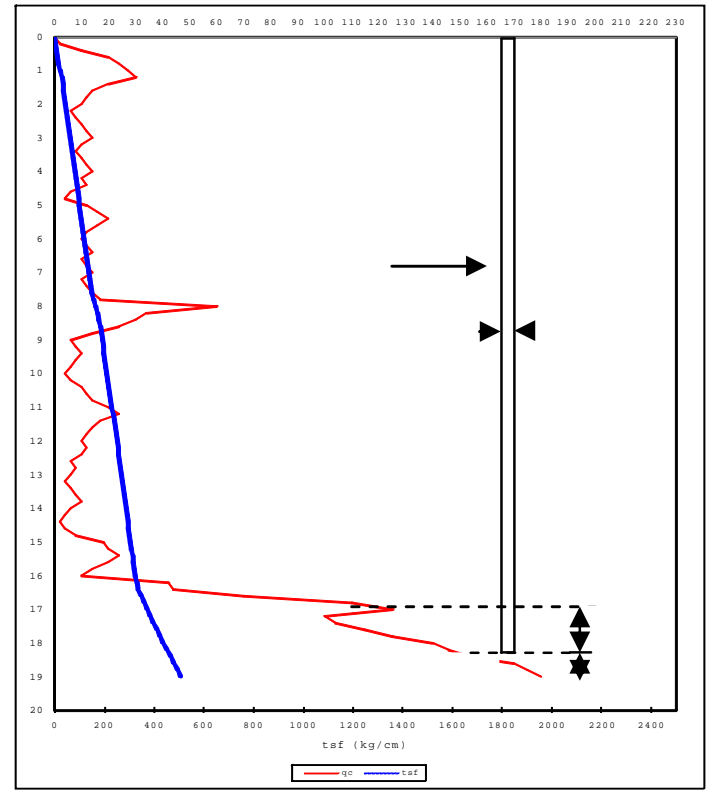

Gambar 7. Cara menghitung tahanan ujung metode Meyerhoff diameter tiang $40 \mathrm{~cm}$

Maka :

$$
\begin{aligned}
\mathrm{f}_{\mathrm{b}} & =\omega_{1} \cdot \omega_{2} \cdot \mathrm{q}_{\mathrm{ca}} \\
& =1 \times 1 \times 14840 \mathrm{KN} / \mathrm{m}^{2} \\
& =14840 \mathrm{KN} / \mathrm{m}^{2}(\mathrm{kPa})
\end{aligned}
$$

Untuk tiang bor diambil, nilai $\mathrm{f}_{\mathrm{b}}$ sebesar $70 \%$

$\mathrm{f}_{\mathrm{b}}=70 \% \times 14840 \mathrm{KN} / \mathrm{m}^{2}$

$=10388 \mathrm{KN} / \mathrm{m}^{2}$

b). Tahanan ujung

$$
\begin{aligned}
\mathrm{Q}_{\mathrm{b}} & =A_{\mathrm{b}} \cdot \mathrm{f}_{\mathrm{b}} \\
& =1 / 4 \pi(0,4)^{2} \times 10388 \mathrm{KN} / \mathrm{m}^{2} \\
& =0,1256 \mathrm{~m}^{2} \times 10388 \mathrm{KN} / \mathrm{m}^{2} \\
& =1304,73 \mathrm{KN}
\end{aligned}
$$


c). Tahanan gesek

$$
\begin{aligned}
\mathrm{f}_{\mathrm{s}} & =\mathrm{k}_{\mathrm{c}} \cdot \mathrm{q}_{\mathrm{c}} \Rightarrow \text { nilai } \mathrm{k}_{\mathrm{c}}=0,005 \\
\mathrm{f}_{\mathrm{s} 1} & =0,005 \times 14,9 \\
& =0,075 \mathrm{~kg} / \mathrm{cm}^{2}=7,5 \mathrm{kPa} \\
\mathrm{f}_{\mathrm{s} 2} & =0,005 \times 20,4 \\
& =0,102 \mathrm{~kg} / \mathrm{cm}^{2}=10,2 \mathrm{kPa} \\
\mathrm{f}_{\mathrm{s} 3} & =0,005 \times 146,91 \\
& =0,735 \mathrm{~kg} / \mathrm{cm}^{2}=73,5 \mathrm{kPa} \\
\mathrm{Q}_{\mathrm{s}} & =\Sigma \mathrm{A}_{\mathrm{s}} \cdot \mathrm{f}_{\mathrm{s}} \\
& =\{\pi \times 0,4 \times(5-0) \times 7,5\}+\{\pi \times 0,4 \times(9-5) \times 10,2\}+\{\pi \times 0,4 \times(18,60-9) \times 73,5\} \\
& =984,57 \mathrm{KN}
\end{aligned}
$$

\begin{tabular}{|c|c|c|}
\hline No & Metode yang dipakai & $\begin{array}{c}\text { Nilai Kuat Dukung Ultimit }\left(\mathrm{Q}_{\mathrm{u}}\right) \\
\text { KN }\end{array}$ \\
\hline 1. & Schertmann dan Nottingham & 2026,44 \\
\hline & Meyerhoff & 2289,30 \\
\hline
\end{tabular}

d). Kuat dukung ultimit

$$
\begin{aligned}
\mathrm{Q}_{\mathrm{u}} & =\mathrm{Q}_{\mathrm{b}}+\mathrm{Q}_{\mathrm{s}} \\
& =(1304,73+984,57) \mathrm{KN} \\
& =2289,30 \mathrm{KN}
\end{aligned}
$$

Tabel 7. Perbandingan perhitungan nilai kuat dukung bored pile $\left(\mathrm{Q}_{\mathrm{u}}\right)$

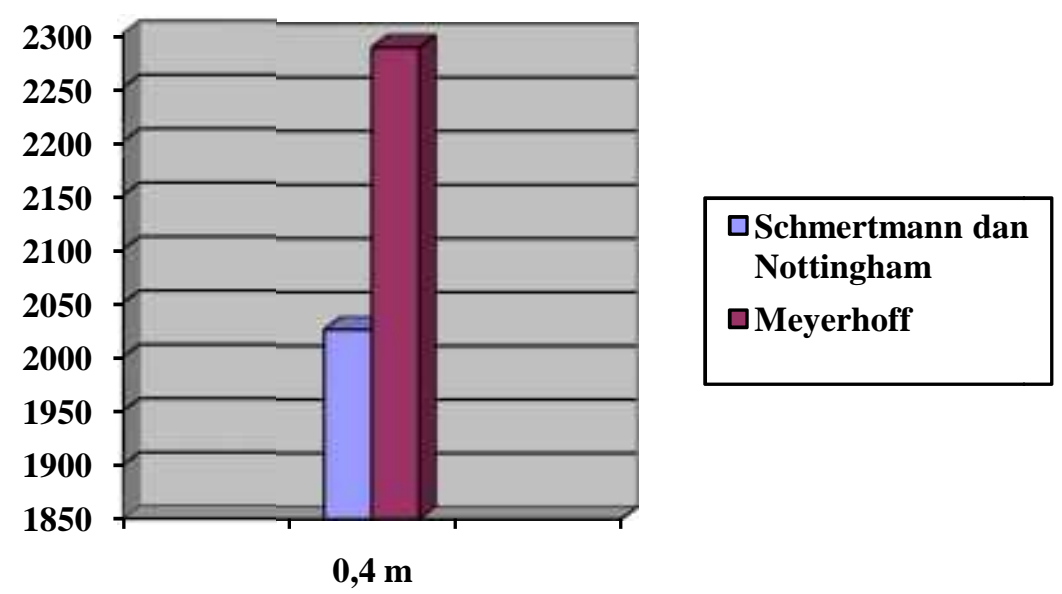

Gambar 8. Grafik perbandingan kuat dukung tiang bored pile antara perhitungan Schmertmann \& Nottinghan dengan Meyerhoff dengan diameter tiang $40 \mathrm{~cm}$

2). Untuk tiang bor berdiameter $60 \mathrm{~cm}(0,6 \mathrm{~m})$

a). Tahanan ujung persatuan luas $\left(\mathrm{f}_{\mathrm{b}}\right)$

$f_{\mathrm{b}}=\omega_{1} \cdot \omega_{2} \cdot q_{\mathrm{ca}}$

$\mathrm{q}_{\mathrm{ca}}=126,87 \mathrm{~kg} / \mathrm{cm}^{2}=12687 \mathrm{KN} / \mathrm{m}^{2}$

Karna $d=0,6 \mathrm{~m}>0,5 \mathrm{~m}$ maka nilai $\omega_{1}$ dapat dihitung :

$\omega_{1}=[(\mathrm{d}+0,5) / 2 \mathrm{~d}]^{\mathrm{n}}$

$\omega_{1}=[(0,6+0,5) / 2(0,6)]^{1}$

$\omega_{1}=0,92$ 
dan $\mathrm{L}>10 \mathrm{~d}$, nilai $\omega_{2}=1$

Maka :

$$
\begin{aligned}
\mathrm{f}_{\mathrm{b}} & =\omega_{1} \cdot \omega_{2} \cdot \mathrm{q}_{\mathrm{ca}} \\
& =0,92 \times 1 \times 12687 \mathrm{KN} / \mathrm{m}^{2} \\
& =11672,04 \mathrm{KN} / \mathrm{m}^{2}(\mathrm{kPa})
\end{aligned}
$$

Untuk tiang bor diambil, nilai $\mathrm{f}_{\mathrm{b}}$ sebesar $70 \%$

$$
\begin{aligned}
\mathrm{f}_{\mathrm{b}} & =70 \% \times 11672,04 \mathrm{KN} / \mathrm{m}^{2} \\
& =8170,43 \mathrm{KN} / \mathrm{m}^{2}
\end{aligned}
$$

b). Tahanan ujung

$$
\begin{aligned}
\mathrm{Q}_{\mathrm{b}} & =\mathrm{A}_{\mathrm{b}} \cdot \mathrm{f}_{\mathrm{b}} \\
& =1 / 4 \pi(0,6)^{2} \times 8170,43 \mathrm{KN} / \mathrm{m}^{2} \\
& =0,2826 \mathrm{~m}^{2} \times 8170,43 \mathrm{KN} / \mathrm{m}^{2} \\
& =2308,96 \mathrm{KN}
\end{aligned}
$$

c). Tahanan gesek

$$
\begin{aligned}
\mathrm{f}_{\mathrm{s}} & =\mathrm{k}_{\mathrm{c}} \cdot \mathrm{q}_{\mathrm{c}} \Rightarrow \text { nilai } \mathrm{k}_{\mathrm{c}}=0,005 \\
\mathrm{f}_{\mathrm{s} 1} & =0,005 \times 14,9 \\
& =0,075 \mathrm{~kg} / \mathrm{cm}^{2}=7,5 \mathrm{kPa} \\
\mathrm{f}_{\mathrm{s} 2} & =0,005 \times 20,4 \\
& =0,102 \mathrm{~kg} / \mathrm{cm}^{2}=10,2 \mathrm{kPa} \\
\mathrm{f}_{\mathrm{s} 3} & =0,005 \times 146,91 \\
& =0,735 \mathrm{~kg} / \mathrm{cm}^{2}=73,5 \mathrm{kPa} \\
\mathrm{Q}_{\mathrm{s}} & =\Sigma \mathrm{A}_{\mathrm{s}} \cdot \mathrm{f}_{\mathrm{s}} \\
& =\{\pi \times 0,6 \times(5-0) \times 7,5\}+\{\pi \times 0,6 \times(9-5) \times 10,2\}+\{\pi \times 0,6 \times(18,60-9) \times 73,5\} \\
& =\{70,65+76,87+1329,35\} \\
& =1476,87 \mathrm{KN}
\end{aligned}
$$

d). Kuat dukung ultimit

$$
\begin{aligned}
\mathrm{Q}_{\mathrm{u}} & =\mathrm{Q}_{\mathrm{b}}+\mathrm{Q}_{\mathrm{s}} \\
& =(2308,96+1476,87) \mathrm{KN} \\
& =3785,83 \mathrm{KN}
\end{aligned}
$$

3). Untuk tiang bor berdiameter $80 \mathrm{~cm}(0,8 \mathrm{~m})$

a). Tahanan ujung persatuan luas $\left(f_{b}\right)$

$\mathrm{f}_{\mathrm{b}}=\omega_{1} \cdot \omega_{2} \cdot \mathrm{q}_{\mathrm{ca}}$

$\mathrm{q}_{\mathrm{ca}}=100,10 \mathrm{~kg} / \mathrm{cm}^{2}=10010 \mathrm{KN} / \mathrm{m}^{2}$

Karna $\mathrm{d}=0,6 \mathrm{~m}>0,5 \mathrm{~m}$ maka nilai $\omega_{1}$ dapat dihitung :

$$
\begin{aligned}
& \omega_{1}=[(\mathrm{d}+0,5) / 2 \mathrm{~d}]^{\mathrm{n}} \\
& \omega_{1}=[(0,8+0,5) / 2(0,8)]^{1} \\
& \omega_{1}=0,81 \\
& \text { dan } \mathrm{L}>10 \mathrm{~d} \text {, nilai } \omega_{2}=1
\end{aligned}
$$


Maka :

$$
\begin{aligned}
\mathrm{f}_{\mathrm{b}} & =\omega_{1} \cdot \omega_{2} \cdot \mathrm{q}_{\mathrm{ca}} \\
& =0,81 \times 1 \times 10010 \mathrm{KN} / \mathrm{m}^{2} \\
& =8108,10 \mathrm{KN} / \mathrm{m}^{2}(\mathrm{kPa})
\end{aligned}
$$

Untuk tiang bor diambil, nilai $\mathrm{f}_{\mathrm{b}}$ sebesar $70 \%$

$$
\begin{aligned}
\mathrm{f}_{\mathrm{b}} & =70 \% \times 8108,10 \mathrm{KN} / \mathrm{m}^{2} \\
& =5675,67 \mathrm{KN} / \mathrm{m}^{2}
\end{aligned}
$$

b). Tahanan ujung

$$
\begin{aligned}
\mathrm{Q}_{\mathrm{b}} & =\mathrm{A}_{\mathrm{b}} \cdot \mathrm{f}_{\mathrm{b}} \\
& =1 / 4 \pi(0,8)^{2} \times 5675,67 \mathrm{KN} / \mathrm{m}^{2} \\
& =0,5024 \mathrm{~m}^{2} \times 5675,67 \mathrm{KN} / \mathrm{m}^{2} \\
& =2851,46 \mathrm{KN}
\end{aligned}
$$

c). Tahanan gesek

$$
\begin{aligned}
\mathrm{f}_{\mathrm{s}} & =\mathrm{k}_{\mathrm{c}} \cdot \mathrm{q}_{\mathrm{c}} \Rightarrow \text { nilai } \mathrm{k}_{\mathrm{c}}=0,005 \\
\mathrm{f}_{\mathrm{s} 1} & =0,005 \times 14,9 \\
& =0,075 \mathrm{~kg} / \mathrm{cm}^{2}=7,5 \mathrm{kPa} \\
\mathrm{f}_{\mathrm{s} 2} & =0,005 \times 20,4 \\
& =0,102 \mathrm{~kg} / \mathrm{cm}^{2}=10,2 \mathrm{kPa} \\
\mathrm{f}_{\mathrm{s} 3} & =0,005 \times 146,91 \\
& =0,735 \mathrm{~kg} / \mathrm{cm}^{2}=73,5 \mathrm{kPa} \\
\mathrm{Q}_{\mathrm{s}} & =\Sigma \mathrm{A}_{\mathrm{s}} \cdot \mathrm{f}_{\mathrm{s}} \\
& =\{\pi \times 0,8 \times(5-0) \times 7,5\}+\{\pi \times 0,8 \times(9-5) \times 10,2\}+\{\pi \times 0,8 \times(18,60-9) \times 73,5\} \\
& =\{94,20+102,49+1772,47\} \\
& =1969,16 \mathrm{KN}
\end{aligned}
$$

d). Kuat dukung ultimit

$$
\begin{aligned}
\mathrm{Q}_{\mathrm{u}} & =\mathrm{Q}_{\mathrm{b}}+\mathrm{Q}_{\mathrm{s}} \\
& =(2851,46+1969,16) \mathrm{KN} \\
& =4820,62 \mathrm{KN}
\end{aligned}
$$

Dari ketiga ukuran diameter tiang bored pile dengan memakai 2 (dua) metode perhitungan Schmertmann \& Nottingham dan Meyerhoff dapat dilihat perbandingan kuat dukung ultimit pondasi tiang bored pile berdasarkan data, persentase perhitungan dengan metode Schertmann dan Nottingham lebih optimis $\pm 6,24 \%$ dibanding dengan memakai metode Meyerhoff yang bersifat konservatif. 


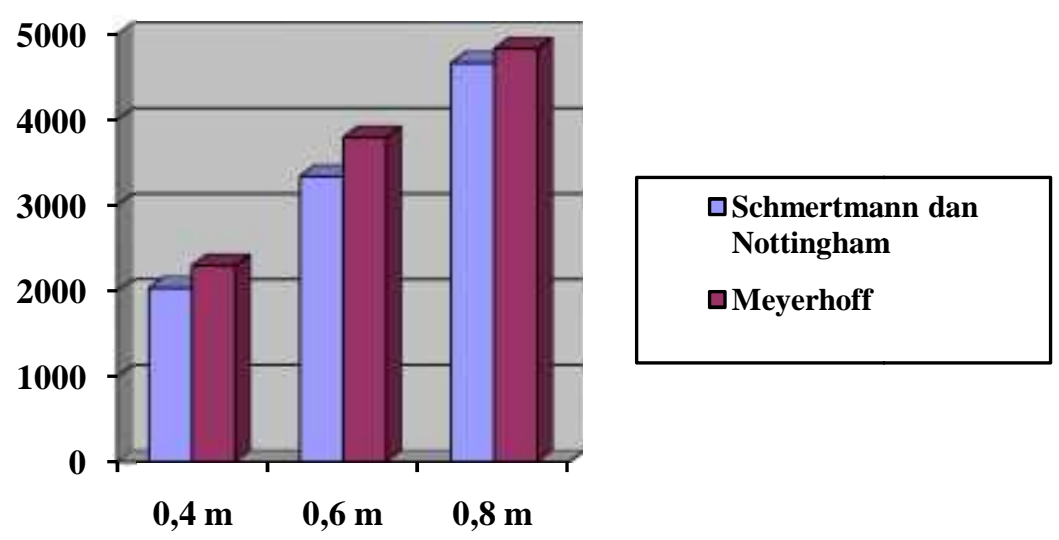

Gambar 9. Grafik perbandingan kuat dukung tiang bored pile antara perhitungan Schmertmann \& Nottinghan dengan Meyerhoff

\section{Menghitung Kapasitas Kuat Dukung Bored Pile dari Data $N-S P T$}

a. Metode O'Neil dan Reese

1). Untuk tiang bor berdiameter $40 \mathrm{~cm}(0,4 \mathrm{~m})$

Tabel 8. Nilai $\mathrm{N}_{60}$ rata-rata terhadap kedalaman pada tanah berpasir

\begin{tabular}{ccc}
\hline Tanah & Kedalaman $(\mathrm{m})$ & $\mathrm{N}_{60}$ rata-rata \\
\hline \multirow{3}{*}{ Pasir } & $0-1,80$ & 1 \\
\cline { 2 - 3 } & $1,80-17,50$ & 1 \\
\cline { 2 - 3 } & $17,50-20,00$ & 17 \\
\hline
\end{tabular}

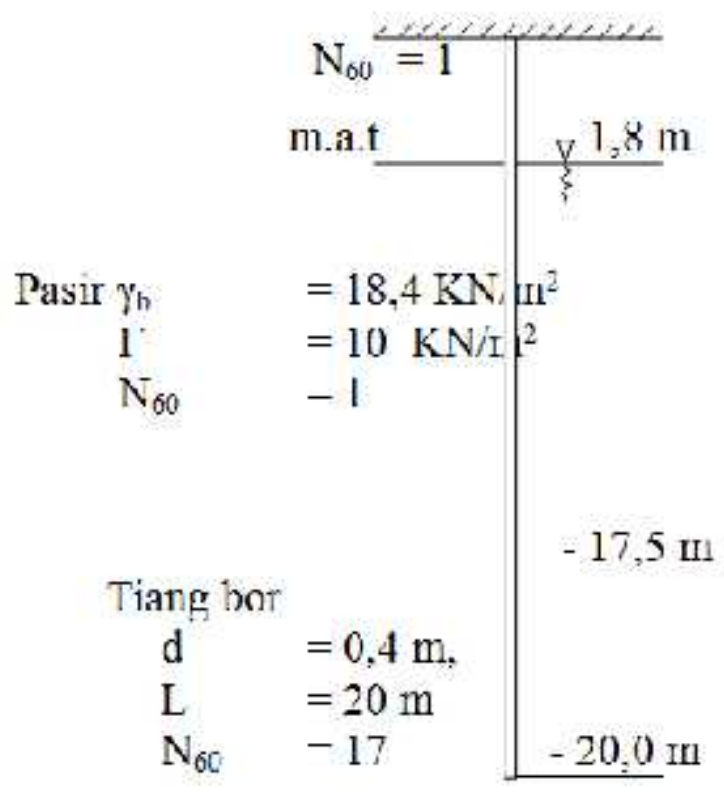

Gambar 10. Nilai $\mathrm{N}_{60}$ rata-rata berdasarkan kedalaman 
a). Tahanan ujung

Luas dasar tiang :

$$
\begin{aligned}
\mathrm{A}_{\mathrm{b}} & =1 / 4 \pi(\mathrm{d})^{2} \\
& =1 / 4 \pi(0,4)^{2} \\
& =0,1256 \mathrm{~m}^{2} \\
\mathrm{f}_{\mathrm{b}} & =0,60 \cdot \sigma_{\mathrm{r}} \cdot \mathrm{N}_{60} \leq 4500 \mathrm{kPa} \\
\mathrm{f}_{\mathrm{b}} & =0,60 \times 100 \times 17 \leq 4500 \mathrm{kPa} \\
\mathrm{f}_{\mathrm{b}} & =1020 \mathrm{kPa} \leq 4500 \mathrm{kPa} \\
\mathrm{Q}_{\mathrm{b}} & =\mathrm{A}_{\mathrm{b}} \cdot \mathrm{f}_{\mathrm{b}} \\
& =0,1256 \mathrm{~m} 2 \times 1020 \mathrm{kPa} \\
& =128,11 \mathrm{KN}
\end{aligned}
$$

b). Tahanan gesek

Keliling tiang $=\pi \mathrm{d}=\pi \times 0,4 \mathrm{~m}=1,256 \mathrm{~m}$

Tabel 9. Nilai $\sigma_{\mathrm{r}}$ rata-rata terhadap kedalaman pada tanah berpasir $(\mathrm{d}=40 \mathrm{~cm})$

\begin{tabular}{ccll}
\hline $\begin{array}{c}\text { Kedalaman } \\
(\mathrm{m})\end{array}$ & $\begin{array}{c}\mathrm{A}_{\mathrm{s}} \\
\left(\mathrm{m}^{2}\right)\end{array}$ & \multicolumn{1}{c}{$\begin{array}{c}\text { Tekanan Overburden Efektif } \\
\left(\mathrm{KN} / \mathrm{m}^{2}\right)\end{array}$} & \multicolumn{1}{c}{$\begin{array}{c}\sigma_{\mathrm{r}} \\
\left(\mathrm{KN} / \mathrm{m}^{2}\right)\end{array}$} \\
\hline 1,80 & 2,30 & $1,80 \times 18,40=33,12$ & $1 / 2[0+33,12]=16,56$ \\
17,50 & 19,70 & $33,12+[15,70 \times(18,40-10)]=165$ & $1 / 2[33,12+165]=99,06$ \\
20,00 & 3,20 & $165+[2,50 \times(18,40-10)]=186$ & $1 / 2[165+186]=175,50$ \\
\hline \multicolumn{3}{c}{ Jumlah } & $\Delta \mathrm{Qs}=\mathbf{3 4 8 , 1 0} \mathrm{KN}$ \\
\hline
\end{tabular}

Untuk kedalaman $0-1,80 \mathrm{~m}, \mathrm{~N}_{60}=1<15$, maka $\beta$ dapat dihitung :

$$
\begin{aligned}
& \beta=\frac{\mathrm{N} 60}{15}\left(1,50-0,245 \sqrt{\mathrm{Z}_{1}}\right) \\
& \beta=\frac{1}{15}(1,50-0,245 \sqrt{0,9}) \\
& \beta=0,0845 \approx 0,09
\end{aligned}
$$

Untuk kedalaman $1,80-17,50 \mathrm{~m}, \mathrm{~N}_{60}=1<15$, maka $\beta$ dapat dihitung :

$$
\begin{aligned}
\beta & =\frac{\mathrm{N} 60}{15}\left(1,50-0,245 \sqrt{\mathrm{Z}_{2}}\right) \\
\beta & =\frac{1}{15}(1,50-0,245 \sqrt{9,65}) \\
\beta & =0,049 \approx 0,05
\end{aligned}
$$

Untuk kedalaman $17,50-20,00 \mathrm{~m}, \mathrm{~N}_{60}=17>15$, maka $\beta$ dapat dihitung:

$$
\begin{aligned}
& \beta=\left(1,50-0,245 \sqrt{Z_{3}}\right), \text { dengan } 0,25 \leq \beta \leq 1,20 \\
& \beta=(1,50-0,245 \sqrt{18,75}) \\
& \beta=0,44
\end{aligned}
$$

c). Kapasitas kuat dukung ultimit

$$
\begin{aligned}
\mathrm{Q}_{\mathrm{u}} & =\mathrm{Q}_{\mathrm{b}}+\mathrm{Q}_{\mathrm{s}} \\
& =128,11+348,10 \\
& =476,21 \mathrm{KN}
\end{aligned}
$$


2). Untuk tiang bor berdiameter $60 \mathrm{~cm}(0,6 \mathrm{~m})$

a). Tahanan ujung

Luas dasar tiang:

$$
\begin{aligned}
\mathrm{A}_{\mathrm{b}} & =1 / 4 \pi(\mathrm{d})^{2} \\
& =1 / 4 \pi(0,6)^{2} \\
& =0,2826 \mathrm{~m}^{2} \\
\mathrm{f}_{\mathrm{b}} & =0,60 \cdot \sigma_{\mathrm{r}} \cdot \mathrm{N}_{60} \leq 4500 \mathrm{kPa} \\
\mathrm{f}_{\mathrm{b}} & =0,60 \times 100 \times 17 \leq 4500 \mathrm{kPa} \\
\mathrm{f}_{\mathrm{b}} & =1020 \mathrm{kPa} \leq 4500 \mathrm{kPa} \\
\mathrm{Q}_{\mathrm{b}} & =\mathrm{A}_{\mathrm{b}} \cdot \mathrm{f}_{\mathrm{b}} \\
& =0,2826 \mathrm{~m} 2 \times 1020 \mathrm{kPa} \\
& =288,25 \mathrm{KN}
\end{aligned}
$$

\begin{tabular}{|c|c|c|c|}
\hline $\begin{array}{l}\text { Interval kedalaman } \\
(\mathrm{m})\end{array}$ & $\begin{array}{l}\mathrm{Z} \\
(\mathrm{m})\end{array}$ & $\beta$ & $\begin{array}{c}\Delta \mathrm{Q}_{\mathrm{s}}=\mathrm{A}_{\mathrm{s}} \beta \sigma_{\mathrm{r}} \text { rata-rata } \\
(\mathrm{KN})\end{array}$ \\
\hline $0-1,80$ & 0,90 & 0,09 & $3,39 \times 0,09 \times 16,56=5,05$ \\
\hline $1,80-17,50$ & 9,65 & 0,05 & $29,58 \times 0,05 \times 99,06=146,51$ \\
\hline $17,50-20,00$ & 18,75 & 0,44 & $4,71 \times 0,44 \times 175,50=363,71$ \\
\hline \multicolumn{3}{|c|}{ Jumlah } & $\Delta \mathrm{Qs}=515,27 \mathrm{KN}$ \\
\hline
\end{tabular}

b). Tahanan gesek

Keliling tiang $=\pi \mathrm{d}=\pi \times 0,6 \mathrm{~m}=1,884 \mathrm{~m}$

Tabel 10. Nilai $\sigma_{\mathrm{r}}$ rata-rata terhadap kedalaman pada tanah berpasir $(\mathrm{d}=60 \mathrm{~cm})$

\begin{tabular}{cccc}
\hline $\begin{array}{c}\text { Kedalaman } \\
(\mathrm{m})\end{array}$ & $\begin{array}{c}\mathrm{A}_{\mathrm{s}} \\
\left(\mathrm{m}^{2}\right)\end{array}$ & $\begin{array}{c}\text { Tekanan } \text { Overburden efektif } \\
\left(\mathrm{KN} / \mathrm{m}^{2}\right)\end{array}$ & $\begin{array}{c}\sigma_{\mathrm{r}} \\
\left(\mathrm{KN} / \mathrm{m}^{2}\right)\end{array}$ \\
\hline 1,80 & 3,39 & $1,80 \times 18,40=33,12$ & $1 / 2[0+33,12]=16,56$ \\
17,50 & 29,58 & $33,12+[15,70 \times(18,40-10)]=165$ & $1 / 2[33,12+165]=99,06$ \\
20,00 & 4,71 & $165+[2,50 \times(18,40-10)]=186$ & $1 / 2[165+186]=175,50$ \\
\hline
\end{tabular}

Tabel 11. Perhitungan nilai tahanan gesek $Q_{s}(d=60 \mathrm{~cm})$

Untuk kedalaman $0-1,80 \mathrm{~m}, \mathrm{~N}_{60}=1<15$, maka $\beta$ dapat dihitung :

$$
\begin{aligned}
& \beta=\frac{\mathrm{N} 60}{15}\left(1,50-0,245 \sqrt{\mathrm{Z}_{1}}\right) \\
& \beta=\frac{1}{15}(1,50-0,245 \sqrt{0,9}) \\
& \beta=0,0845 \approx 0,09
\end{aligned}
$$

Untuk kedalaman $1,80-17,50 \mathrm{~m}, \mathrm{~N}_{60}=1<15$, maka $\beta$ dapat dihitung :

$$
\begin{aligned}
& \beta=\frac{\mathrm{N} 60}{15}\left(1,50-0,245 \sqrt{\mathrm{Z}_{2}}\right) \\
& \beta=\frac{1}{15}(1,50-0,245 \sqrt{9,65}) \\
& \beta=0,049 \approx 0,05
\end{aligned}
$$


Untuk kedalaman $17,50-20,00 \mathrm{~m}, \mathrm{~N}_{60}=17>15$, maka $\beta$ dapat dihitung:

$$
\begin{aligned}
& \beta=\left(1,50-0,245 \sqrt{Z_{3}}\right), \text { dengan } 0,25 \leq \beta \leq 1,20 \\
& \beta=(1,50-0,245 \sqrt{18,75}) \\
& \beta=0,44
\end{aligned}
$$

c). Kapasitas kuat dukung ultimit

$$
\begin{aligned}
\mathrm{Q}_{\mathrm{u}} & =\mathrm{Q}_{\mathrm{b}}+\mathrm{Q}_{\mathrm{s}} \\
& =288,25+515,27 \\
& =803,52 \mathrm{KN}
\end{aligned}
$$

3). Untuk tiang bor berdiameter $80 \mathrm{~cm}(0,8 \mathrm{~m})$

a). Tahanan ujung

Luas dasar tiang :

$$
\begin{aligned}
\mathrm{A}_{\mathrm{b}} & =1 / 4 \pi(\mathrm{d})^{2} \\
& =1 / 4 \pi(0,8)^{2} \\
& =0,5024 \mathrm{~m}^{2} \\
\mathrm{f}_{\mathrm{b}} & =0,60 \cdot \sigma_{\mathrm{r}} \cdot \mathrm{N}_{60} \leq 4500 \mathrm{kPa} \\
\mathrm{f}_{\mathrm{b}} & =0,60 \times 100 \times 17 \leq 4500 \mathrm{kPa} \\
\mathrm{f}_{\mathrm{b}} & =1020 \mathrm{kPa} \leq 4500 \mathrm{kPa} \\
\mathrm{Q}_{\mathrm{b}} & =\mathrm{A}_{\mathrm{b}} \cdot \mathrm{f}_{\mathrm{b}} \\
& =0,5024 \mathrm{~m} 2 \times 1020 \mathrm{kPa} \\
& =512,45 \mathrm{KN}
\end{aligned}
$$

\begin{tabular}{|c|c|c|c|}
\hline $\begin{array}{l}\text { Interval kedalaman } \\
(\mathrm{m})\end{array}$ & $\begin{array}{c}\mathrm{Z} \\
(\mathrm{m})\end{array}$ & $\beta$ & $\begin{array}{c}\Delta \mathrm{Q}_{\mathrm{s}}=\mathrm{A}_{\mathrm{s}} \beta \sigma_{\mathrm{r}} \text { rata-rata } \\
(\mathrm{KN})\end{array}$ \\
\hline $0-1,80$ & 0,90 & 0,09 & $4,52 \times 0,09 \times 16,56=6,74$ \\
\hline $1,80-17,50$ & 9,65 & 0,05 & $39,44 \times 0,05 \times 99,06=195,35$ \\
\hline $17,50-20,00$ & 18,75 & 0,44 & $6,28 \times 0,44 \times 175,50=484,94$ \\
\hline \multicolumn{3}{|c|}{ Jumlah } & $\Delta \mathrm{Q}_{\mathrm{s}}=687,03 \mathrm{KN}$ \\
\hline
\end{tabular}

b). Tahanan gesek

Keliling tiang $=\pi \mathrm{d}=\pi \times 0,8 \mathrm{~m}=2,512 \mathrm{~m}$

Tabel 12. Nilai $\sigma_{\mathrm{r}}$ rata-rata terhadap kedalaman pada tanah berpasir $(\mathrm{d}=80 \mathrm{~cm})$

\begin{tabular}{cccc}
\hline $\begin{array}{c}\text { Kedalaman } \\
(\mathrm{m})\end{array}$ & $\begin{array}{c}\mathrm{A}_{\mathrm{s}} \\
\left(\mathrm{m}^{2}\right)\end{array}$ & \multicolumn{1}{c}{$\begin{array}{c}\text { Tekanan } \text { Overburden efektif } \\
\left(\mathrm{KN} / \mathrm{m}^{2}\right)\end{array}$} & $\begin{array}{c}\sigma_{\mathrm{r}} \\
\sigma_{\mathrm{r}} \text { rata-rata } \\
\left(\mathrm{KN} / \mathrm{m}^{2}\right)\end{array}$ \\
\hline 1,80 & 4,52 & $1,80 \times 18,40=33,12$ & $1 / 2[0+33,12]=16,56$ \\
17,50 & 39,44 & $33,12+[15,70 \times(18,40-10)]=165$ & $1 / 2[33,12+165]=99,06$ \\
20,00 & 6,28 & $165+[2,50 \times(18,40-10)]=186$ & $1 / 2[165+186]=175,50$ \\
\hline
\end{tabular}

Tabel 13. Perhitungan nilai tahanan gesek $\Delta \mathrm{Q}_{\mathrm{s}}(\mathrm{d}=80 \mathrm{~cm})$

Untuk kedalaman $0-1,80 \mathrm{~m}, \mathrm{~N}_{60}=1<15$, maka $\beta$ dapat dihitung :

$$
\begin{aligned}
& \beta=\frac{\mathrm{N} 60}{15}\left(1,50-0,245 \sqrt{\mathrm{Z}_{1}}\right) \\
& \beta=\frac{1}{15}(1,50-0,245 \sqrt{0,9}) \\
& \beta=0,0845 \approx 0,09
\end{aligned}
$$


Untuk kedalaman $1,80-17,50 \mathrm{~m}, \mathrm{~N}_{60}=1<15$, maka $\beta$ dapat dihitung :

$$
\begin{aligned}
& \beta=\frac{\mathrm{N} 60}{15}\left(1,50-0,245 \sqrt{\mathrm{Z}_{2}}\right) \\
& \beta=\frac{1}{15}(1,50-0,245 \sqrt{9,65}) \\
& \beta=0,049 \approx 0,05
\end{aligned}
$$

Untuk kedalaman $17,50-20,00 \mathrm{~m}, \mathrm{~N}_{60}=17>15$, maka $\beta$ dapat dihitung:

$$
\begin{aligned}
& \beta=\left(1,50-0,245 \sqrt{Z_{3}}\right), \text { dengan } 0,25 \leq \beta \leq 1,20 \\
& \beta=(1,50-0,245 \sqrt{18,75}) \\
& \beta=0,44
\end{aligned}
$$

\begin{tabular}{|c|c|c|c|c|}
\hline No & $\begin{array}{c}\text { Diameter } \\
\text { Tiang }(\mathrm{d}) \\
\mathrm{Cm}\end{array}$ & $\begin{array}{c}\text { Tahanan } \\
\text { ujung }\left(\mathrm{Q}_{\mathrm{b}}\right) \\
\mathrm{KN}\end{array}$ & $\begin{array}{c}\text { Tahanan } \\
\text { gesek }\left(Q_{\mathrm{s}}\right) \\
\text { KN }\end{array}$ & $\begin{array}{c}\text { Kuat dukung } \\
\text { ultimit }\left(\mathrm{Q}_{\mathrm{u}}\right) \\
\mathrm{KN}\end{array}$ \\
\hline 1. & 40 & 128,11 & 348,10 & 476,21 \\
\hline 2. & 60 & 288,25 & 515,27 & 803,52 \\
\hline 3. & 80 & 512,45 & 687,03 & 1199,48 \\
\hline
\end{tabular}

c). Kapasitas kuat dukung ultimit

$$
\begin{aligned}
\mathrm{Q}_{\mathrm{u}} & =\mathrm{Q}_{\mathrm{b}}+\mathrm{Q}_{\mathrm{s}} \\
& =512,45+687,03 \\
& =1199,48 \mathrm{KN}
\end{aligned}
$$

Tabel 14. Perhitungan kuat dukung bored pile dengan metode O'Neil dan Reese dari beberapa diameter tiang

b. Metode Meyerhoff

1). Kuat dukung ultimit, diameter tiang $\mathrm{d}=40 \mathrm{~cm}(0,4 \mathrm{~m})$

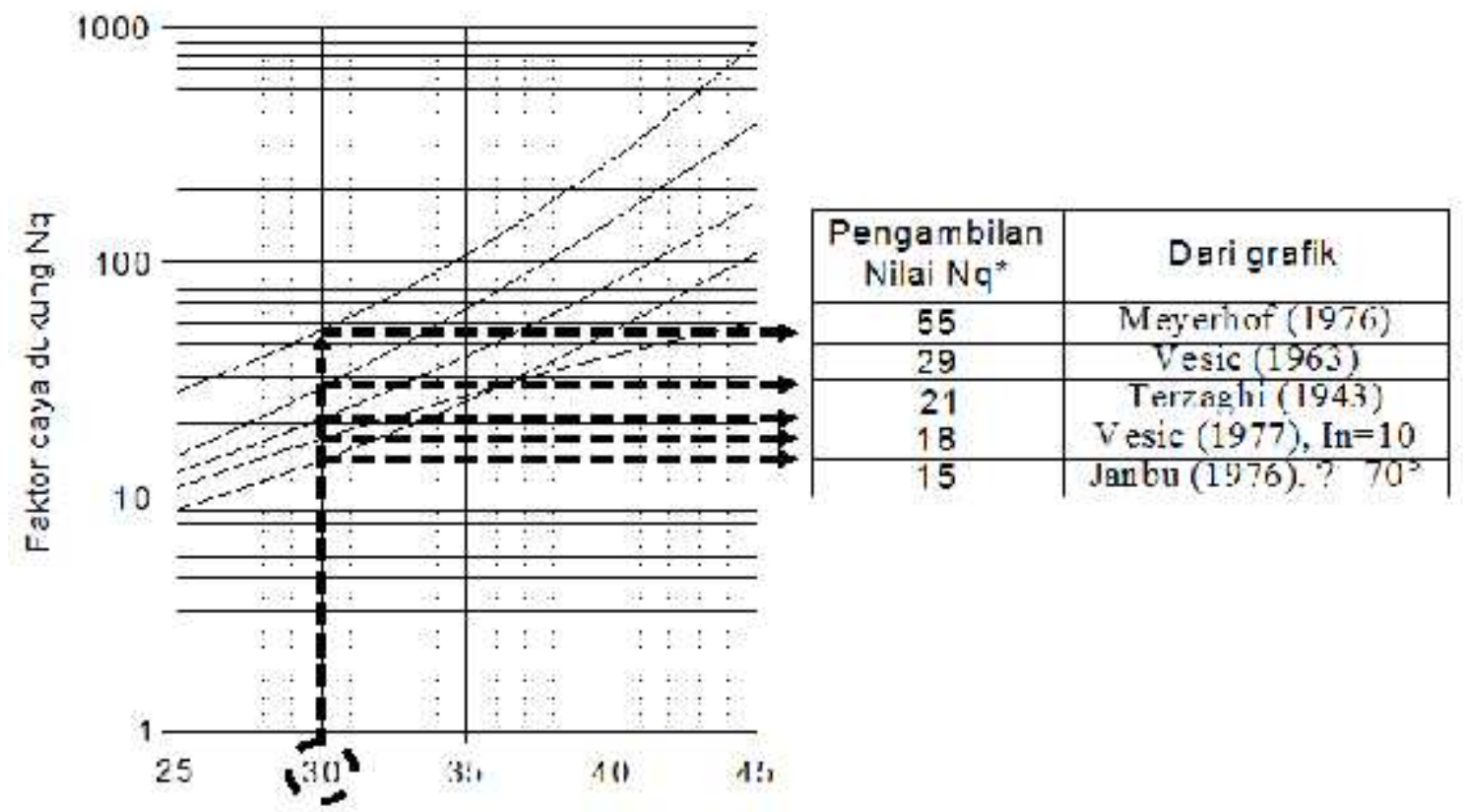

Gambar 11. Nilai faktor kuat dukung ujung dengan $\Phi=30^{\circ}$ 
a). Tahanan ujung ultimit

$$
\begin{aligned}
\mathrm{Q}_{\mathrm{b}} & =\mathrm{A}_{\mathrm{b}} \cdot \mathrm{q}_{\mathrm{b}} \\
\mathrm{q}_{\mathrm{b}} & =\sigma_{\mathrm{r}} \cdot \mathrm{N}_{\mathrm{q}} * \mathrm{~N}_{\mathrm{q}} *=55 \\
\Phi & =30 \\
\mathrm{q}_{\mathrm{b}} & =175,50 \times 55 \\
& =9652,50 \mathrm{KN} / \mathrm{m}^{2} \\
\mathrm{~A}_{\mathrm{b}} & =1 / 4 \pi(\mathrm{d})^{2} \\
& =1 / 4 \pi(0,4)^{2} \\
& =0,1256 \mathrm{~m}^{2} \\
\mathrm{Q}_{\mathrm{b}} & =\mathrm{A}_{\mathrm{b}} \cdot \mathrm{q}_{\mathrm{b}} \\
& =0,1256 \times 9652,50 \\
& =1212,35 \mathrm{KN}
\end{aligned}
$$

b). Tahanan gesek ultimit

$$
\mathrm{Q}_{\mathrm{s}}=\Sigma \mathrm{A}_{\mathrm{s}} \cdot \mathrm{q}_{\mathrm{s}}
$$

Dari tabel didapat luasan selimut tiang masing-masing kedalaman yaitu : kedalaman $0-1,80 \mathrm{~m}$ luas selimut tiang $\mathrm{A}_{\mathrm{s} 1}=2,30 \mathrm{~m}^{2}$; kedalaman 1,80 $17,50 \mathrm{~m}$ luas selimut tiang $\mathrm{A}_{\mathrm{s} 2}=19,70 \mathrm{~m}^{2}$; kedalaman $17,50-20,00 \mathrm{~m}$ luas selimut tiang $\mathrm{A}_{\mathrm{s} 3}=3,20 \mathrm{~m}^{2}$

$$
\begin{aligned}
\delta & =\Phi=30^{\circ} \\
\mathrm{K} & =1-\sin \Phi=1-\sin 30^{\circ}=0,5 \\
\mathrm{q}_{\mathrm{s} 1} & =\mathrm{K} \sigma_{\mathrm{r} 1} \cdot \tan \delta \\
& =0,5 \times 16,56 \times \tan 30^{\circ} \\
& =4,78 \mathrm{KN} / \mathrm{m}^{2} \\
\mathrm{q}_{\mathrm{s} 2} & =\mathrm{K} \sigma_{\mathrm{r} 2} \cdot \tan \delta \\
& =0,5 \times 99,06 \times \tan 30^{\circ} \\
& =28,60 \mathrm{KN} / \mathrm{m}^{2} \\
\mathrm{q}_{\mathrm{s} 3} & =\mathrm{K} \sigma_{\mathrm{r} 3} \cdot \tan \delta \\
& =0,5 \times 175,50 \times \tan 30^{\circ} \\
& =50,66 \mathrm{KN} / \mathrm{m}^{2} \\
\mathrm{Q}_{\mathrm{s}} & =\Sigma \mathrm{A}_{\mathrm{s}} \cdot \mathrm{q}_{\mathrm{s}} \\
& =\left(\mathrm{A}_{\mathrm{s} 1} \cdot \mathrm{q}_{\mathrm{s} 1}+\mathrm{A}_{\mathrm{s} 2} \cdot \mathrm{q}_{\mathrm{s} 2}+\mathrm{A}_{\mathrm{s} 3} \cdot \mathrm{q}_{\mathrm{s} 3}\right) \\
& =(2,30 \times 4,78)+(19,70 \times 28,60)+(3,20 \times 50,66) \\
& =(10,99+563,42+162,11) \\
& =736,52 \mathrm{KN}
\end{aligned}
$$

c). Kapasitas kuat dukung ultimit

$$
\begin{aligned}
\mathrm{Q}_{\mathrm{u}} & =\mathrm{Q}_{\mathrm{b}}+\mathrm{Q}_{\mathrm{s}} \\
& =1212,35+736,52 \\
& =1948,87 \mathrm{KN}
\end{aligned}
$$

2). Kuat dukung ultimit ,diameter tiang $\mathrm{d}=60 \mathrm{~cm}(0,6 \mathrm{~m})$

$$
\mathrm{Q}_{\mathrm{u}}=\mathrm{Q}_{\mathrm{b}}+\mathrm{Q}_{\mathrm{s}}
$$

a). Tahanan ujung ultimit

$$
\begin{aligned}
& \mathrm{Q}_{\mathrm{b}}=\mathrm{A}_{\mathrm{b}} \cdot \mathrm{q}_{\mathrm{b}} \\
& \mathrm{q}_{\mathrm{b}}=\sigma_{\mathrm{r}} \cdot \mathrm{N}_{\mathrm{q}} * \mathrm{~N}_{\mathrm{q}} *=55
\end{aligned}
$$




$$
\begin{aligned}
\Phi & =30^{\circ} \\
\mathrm{q}_{\mathrm{b}} & =175,50 \times 55 \\
& =9652,50 \mathrm{KN} / \mathrm{m}^{2} \\
\mathrm{~A}_{\mathrm{b}} & =1 / 4 \pi(\mathrm{d})^{2} \\
& =1 / 4 \pi(0,6)^{2} \\
& =0,2826 \mathrm{~m}^{2} \\
\mathrm{Q}_{\mathrm{b}} & =\mathrm{A}_{\mathrm{b}} \cdot \mathrm{q}_{\mathrm{b}} \\
& =0,2826 \times 9652,50 \\
& =2727,80 \mathrm{KN}
\end{aligned}
$$

b). Tahanan gesek ultimit

$$
\mathrm{Q}_{\mathrm{s}}=\Sigma \mathrm{A}_{\mathrm{s}} \cdot \mathrm{q}_{\mathrm{s}}
$$

Dari tabel didapat luasan selimut tiang masing-masing kedalaman yaitu: kedalaman 0 - 1,80 m luas selimut tiang $\mathrm{A}_{\mathrm{s} 1}=3,39 \mathrm{~m}^{2}$; kedalaman 1,80 $17,50 \mathrm{~m}$ luas selimut tiang $\mathrm{A}_{\mathrm{s} 2}=29,58 \mathrm{~m}^{2}$; kedalaman $17,50-20,00 \mathrm{~m}$ luas selimut tiang $\mathrm{A}_{\mathrm{s} 3}=4,71 \mathrm{~m}^{2}$

$$
\begin{aligned}
\delta & =\Phi=30^{\circ} \\
\mathrm{K} & =1-\sin \Phi=1-\sin 30^{\circ}=0,5 \\
\mathrm{q}_{\mathrm{s} 1} & =\mathrm{K} \sigma_{\mathrm{r} 1} \cdot \tan \delta \\
& =0,5 \times 16,56 \times \tan 30^{\circ} \\
& =4,78 \mathrm{KN} / \mathrm{m}^{2} \\
\mathrm{q}_{\mathrm{s} 2} & =\mathrm{K} \sigma_{\mathrm{r} 2} \cdot \tan \delta \\
& =0,5 \times 99,06 \times \tan 30^{\circ} \\
& =28,60 \mathrm{KN} / \mathrm{m}^{2} \\
\mathrm{q}_{\mathrm{s} 3} & =\mathrm{K} \sigma_{\mathrm{r} 3} \cdot \tan \delta \\
& =0,5 \times 175,50 \times \tan 30^{\circ} \\
& =50,66 \mathrm{KN} / \mathrm{m}^{2} \\
\mathrm{Q}_{\mathrm{s}} & =\Sigma \mathrm{A}_{\mathrm{s}} \cdot \mathrm{q}_{\mathrm{s}} \\
& =\left(\mathrm{A}_{\mathrm{s} 1} \cdot \mathrm{q}_{\mathrm{s} 1}+\mathrm{A}_{\mathrm{s} 2} \cdot \mathrm{q}_{\mathrm{s} 2}+\mathrm{A}_{\mathrm{s} 3} \cdot \mathrm{q}_{\mathrm{s} 3}\right) \\
& =(3,39 \times 4,78)+(29,58 \times 28,60)+(4,71 \times 50,66) \\
& =(16,20+845,99+238,61) \\
& =1100,80 \mathrm{KN}
\end{aligned}
$$

c). Kapasitas kuat dukung ultimit

$$
\begin{aligned}
\mathrm{Q}_{\mathrm{u}} & =\mathrm{Q}_{\mathrm{b}}+\mathrm{Q}_{\mathrm{s}} \\
& =2727,80+1100,80 \\
& =3828,60 \mathrm{KN}
\end{aligned}
$$

3). Kuat dukung ultimit, diameter tiang $\mathrm{d}=80 \mathrm{~cm}(0,8 \mathrm{~m})$

$\mathrm{Q}_{\mathrm{u}}=\mathrm{Q}_{\mathrm{b}}+\mathrm{Q}_{\mathrm{s}}$

a). Tahanan ujung ultimit

$$
\begin{aligned}
\mathrm{Q}_{\mathrm{b}} & =\mathrm{A}_{\mathrm{b}} \cdot \mathrm{q}_{\mathrm{b}} \\
\mathrm{q}_{\mathrm{b}} & =\sigma_{\mathrm{r}} \cdot \mathrm{N}_{\mathrm{q}} * \mathrm{~N}_{\mathrm{q}} *=55 \\
\Phi & =30 \\
\mathrm{q}_{\mathrm{b}} & =175,50 \times 55 \\
& =9652,50 \mathrm{KN} / \mathrm{m}^{2}
\end{aligned}
$$




$$
\begin{aligned}
\mathrm{A}_{\mathrm{b}} & =1 / 4 \pi(\mathrm{d})^{2} \\
& =1 / 4 \pi(0,8)^{2} \\
& =0,5024 \mathrm{~m}^{2} \\
\mathrm{Q}_{\mathrm{b}} & =\mathrm{A}_{\mathrm{b}} \cdot \mathrm{q}_{\mathrm{b}} \\
& =0,5024 \times 9652,50 \\
& =4849,42 \mathrm{KN}
\end{aligned}
$$

b). Tahanan gesek ultimit

$$
\mathrm{Q}_{\mathrm{s}}=\Sigma \mathrm{A}_{\mathrm{s}} \cdot \mathrm{q}_{\mathrm{s}}
$$

Dari tabel didapat luasan selimut tiang masing-masing kedalaman yaitu : kedalaman $0-1,80 \mathrm{~m}$ luas selimut tiang $\mathrm{A}_{\mathrm{s} 1}=4,52 \mathrm{~m}^{2}$; kedalaman $1,80-$ $17,50 \mathrm{~m}$ luas selimut tiang $\mathrm{A}_{\mathrm{s} 2}=39,44 \mathrm{~m}^{2}$; kedalaman $17,50-20,00 \mathrm{~m}$ luas selimut tiang $\mathrm{A}_{\mathrm{s} 3}=6,28 \mathrm{~m}^{2}$

$$
\begin{aligned}
\delta & =\Phi=30^{\circ} \\
\mathrm{K} & =1-\sin \Phi=1-\sin 30^{\circ}=0,5 \\
\mathrm{q}_{\mathrm{s} 1} & =\mathrm{K} \sigma_{\mathrm{r} 1} \cdot \tan \delta \\
& =0,5 \times 16,56 \times \tan 30^{\circ} \\
& =4,78 \mathrm{KN} / \mathrm{m}^{2} \\
\mathrm{q}_{\mathrm{s} 2} & =\mathrm{K} \sigma_{\mathrm{r} 2} \cdot \tan \delta \\
& =0,5 \times 99,06 \times \tan 30^{\circ} \\
& =28,60 \mathrm{KN} / \mathrm{m}^{2} \\
\mathrm{q}_{\mathrm{s} 3} & =\mathrm{K} \sigma_{\mathrm{r} 3} \cdot \tan \delta \\
& =0,5 \times 175,50 \times \tan 30^{\circ} \\
& =50,66 \mathrm{KN} / \mathrm{m}^{2} \\
\mathrm{Q}_{\mathrm{s}} & =\Sigma \mathrm{A}_{\mathrm{s}} \cdot \mathrm{q}_{\mathrm{s}} \\
& =\left(\mathrm{A}_{\mathrm{s} 1} \cdot \mathrm{q}_{\mathrm{s} 1}+\mathrm{A}_{\mathrm{s} 2} \cdot \mathrm{q}_{\mathrm{s} 2}+\mathrm{A}_{\mathrm{s} 3} \cdot \mathrm{q}_{\mathrm{s} 3}\right) \\
& =(4,52 \times 4,78)+(39,44 \times 28,60)+(6,28 \times 50,66) \\
& =(21,61+1127,98+318,15) \\
& =1467,74 \mathrm{KN}
\end{aligned}
$$

c). Kapasitas kuat dukung ultimit

$$
\begin{aligned}
\mathrm{Q}_{\mathrm{u}} & =\mathrm{Q}_{\mathrm{b}}+\mathrm{Q}_{\mathrm{s}} \\
& =4849,42+1467,74 \\
& =6317,17 \mathrm{KN}
\end{aligned}
$$

Tabel 15. Perhitungan kuat dukung bored pile dengan metode Meyerhoff dari beberapa diameter tiang

\begin{tabular}{ccccc}
\hline No & $\begin{array}{c}\text { Diameter } \\
\text { tiang }(d) \\
\text { cm }\end{array}$ & $\begin{array}{c}\text { Tahanan } \\
\text { ujung }\left(Q_{b}\right) \\
\text { KN }\end{array}$ & $\begin{array}{c}\text { Tahanan } \\
\text { gesek }\left(Q_{s}\right) \\
\text { KN }\end{array}$ & $\begin{array}{c}\text { Kuat dukung } \\
\text { ultimit }\left(Q_{u}\right) \\
\text { KN }\end{array}$ \\
\hline 1. & 40 & 1212,35 & 736,52 & 1948,87 \\
2. & 60 & 2727,80 & 1100,80 & 3828,60 \\
3. & 80 & 4849,42 & 1467,74 & 6317,17 \\
\hline
\end{tabular}


c. Metode Coyle dan Castello

1). Untuk tiang bor berdiameter $40 \mathrm{~cm}(0,4 \mathrm{~m})$

a). Tahanan ujung ultimit

$$
\begin{aligned}
\mathrm{Q}_{\mathrm{b}} & =\mathrm{A}_{\mathrm{b}} \cdot \mathrm{q}_{\mathrm{b}} \\
\mathrm{q}_{\mathrm{b}} & =\sigma_{\mathrm{r}} \cdot \mathrm{N}_{\mathrm{q}} *
\end{aligned}
$$

Nilai $\mathrm{N}_{\mathrm{q}} *$ didapat dari gambar 11 hubungan $\mathrm{L} / \mathrm{D}-\mathrm{N}_{\mathrm{q}} *$, Nilai $\mathrm{N}_{\mathrm{q}} *=20$

$$
\begin{aligned}
\mathrm{q}_{\mathrm{b}} & =175,50 \times 20 \\
& =3510 \mathrm{KN} / \mathrm{m}^{2} \\
\mathrm{~A}_{\mathrm{b}} & =1 / 4 \pi(\mathrm{d})^{2} \\
& =1 / 4 \pi(0,4)^{2} \\
& =0,1256 \mathrm{~m}^{2} \\
\mathrm{Q}_{\mathrm{b}} & =\mathrm{A}_{\mathrm{b} \cdot \mathrm{q}_{\mathrm{b}}} \\
& =0,1256 \times 3510 \\
& =440,86 \mathrm{KN}
\end{aligned}
$$

b). Tahanan Gesek Ultimit

$\mathrm{Q}_{\mathrm{s}}=\mathrm{f}_{\mathrm{av}} \cdot \mathrm{S}$. L

$\mathrm{f}_{\mathrm{av}}=\left(\mathrm{K} \sigma_{\mathrm{r}}, \tan \delta\right) . S . L$

$\delta=\Phi=30^{\circ}$

$\mathrm{K}=0,2$ (didapat dari grafik gambar 11)

Keliling tiang $=\mathrm{S}=\pi \cdot \mathrm{d}=\pi \times 0,4=1,256 \mathrm{~m}$

$\Delta \mathrm{Q}_{\mathrm{s}}=\mathrm{Q}_{\mathrm{s} 1}+\mathrm{Q}_{\mathrm{s} 2}+\mathrm{Q}_{\mathrm{s} 3}$

$\Delta \mathrm{Q}_{\mathrm{s}}=\mathrm{f}_{\mathrm{av} 1} \cdot \mathrm{S} \cdot \mathrm{L}_{1}+\mathrm{f}_{\mathrm{av} 2} \cdot \mathrm{S} \cdot \mathrm{L}_{2}+\mathrm{f}_{\mathrm{av} 3} \cdot$ S. $\cdot \mathrm{L}_{3}$

$\Delta \mathrm{Q}_{\mathrm{s}}=\left(\mathrm{K} \sigma_{\mathrm{r} 1}{ }^{\prime} \tan \delta\right) \cdot \mathrm{S} \cdot \mathrm{L}_{1}+\left(\mathrm{K} \sigma_{\mathrm{r} 2}{ }^{\prime} \tan \delta\right) \cdot \mathrm{S} \cdot \mathrm{L}_{2}+\left(\mathrm{K} \sigma_{\mathrm{r} 3}{ }^{\prime} \tan \delta\right) \cdot S \cdot \mathrm{L}_{3}$

$\mathrm{Q}_{\mathrm{s} 1}=\left(0,2 \times 16,56 \times \tan 30^{\circ}\right) \times 1,256 \times 1,8=4,32 \mathrm{KN}$

$\mathrm{Q}_{\mathrm{s} 2}=\left(0,2 \times 99,06 \times \tan 30^{\circ}\right) \times 1,256 \times 15,7=225,56 \mathrm{KN}$

$\mathrm{Q}_{\mathrm{s} 1}=\left(0,2 \times 175,50 \times \tan 30^{\circ}\right) \times 1,256 \times 2,5=63,63 \mathrm{KN}$

$\Delta \mathrm{Q}_{\mathrm{s}}=4,32+225,56+63,63$

$\Delta \mathrm{Q}_{\mathrm{s}}=293,51 \mathrm{KN}$

c). Kapasitas Kuat Dukung Ultimit

$$
\begin{aligned}
\mathrm{Q}_{\mathrm{u}} & =\mathrm{Q}_{\mathrm{b}}+\mathrm{Q}_{\mathrm{s}} \\
& =440,86+293,51 \\
& =734,37 \mathrm{KN}
\end{aligned}
$$

2). Untuk tiang bor berdiameter $60 \mathrm{~cm}(0,6 \mathrm{~m})$

a). Tahanan Ujung Ultimit

$$
\begin{aligned}
\mathrm{Q}_{\mathrm{b}} & =\mathrm{A}_{\mathrm{b}} \cdot \mathrm{q}_{\mathrm{b}} \\
\mathrm{q}_{\mathrm{b}} & =\sigma_{\mathrm{r}} \cdot \mathrm{N}_{\mathrm{q}} *
\end{aligned}
$$

Nilai $\mathrm{N}_{\mathrm{q}} *$ didapat dari gambar 11 hubungan $\mathrm{L} / \mathrm{D}-\mathrm{N}_{\mathrm{q}} *$, Nilai $\mathrm{N}_{\mathrm{q}} *=20$

$$
\begin{aligned}
\mathrm{q}_{\mathrm{b}} & =175,50 \times 20 \\
& =3510 \mathrm{KN} / \mathrm{m}^{2} \\
\mathrm{~A}_{\mathrm{b}} & =1 / 4 \pi(\mathrm{d})^{2} \\
& =1 / 4 \pi(0,6)^{2} \\
& =0,2826 \mathrm{~m}^{2}
\end{aligned}
$$




$$
\begin{aligned}
\mathrm{Q}_{\mathrm{b}} & =\mathrm{A}_{\mathrm{b}} \cdot \mathrm{q}_{\mathrm{b}} \\
& =0,2826 \times 3510 \\
& =991,93 \mathrm{KN}
\end{aligned}
$$

b). Tahanan Gesek Ultimit

$\mathrm{Q}_{\mathrm{s}}=\mathrm{f}_{\mathrm{av}} . \mathrm{S}$. L

$\mathrm{f}_{\mathrm{av}}=\left(\mathrm{K} \sigma_{\mathrm{r}}, \tan \delta\right) \cdot S \cdot \mathrm{L}$

$\delta=\Phi=30^{\circ}$

$\mathrm{K}=0,2$ (didapat dari grafik gambar 11)

Keliling tiang $=S=\pi \cdot d=\pi \times 0,6=1,884 \mathrm{~m}$

$\Delta \mathrm{Q}_{\mathrm{s}}=\mathrm{Q}_{\mathrm{s} 1}+\mathrm{Q}_{\mathrm{s} 2}+\mathrm{Q}_{\mathrm{s} 3}$

$\Delta \mathrm{Q}_{\mathrm{s}}=\mathrm{f}_{\mathrm{av} 1} \cdot \mathrm{S} \cdot \mathrm{L}_{1}+\mathrm{f}_{\mathrm{av} 2} \cdot \mathrm{S} \cdot \mathrm{L}_{2}+\mathrm{f}_{\mathrm{av} 3} \cdot \mathrm{S} \cdot \mathrm{L}_{3}$

$\Delta \mathrm{Q}_{\mathrm{S}}=\left(\mathrm{K} \sigma_{\mathrm{r} 1}{ }^{\prime} \tan \delta\right) \cdot \mathrm{S} \cdot \mathrm{L}_{1}+\left(\mathrm{K} \sigma_{\mathrm{r} 2}{ }^{\prime} \tan \delta\right) \cdot \mathrm{S} \cdot \mathrm{L}_{2}+\left(\mathrm{K} \sigma_{\mathrm{r} 3}{ }^{\prime} \tan \delta\right) \cdot \mathrm{S} \cdot \mathrm{L}_{3}$

$\mathrm{Q}_{\mathrm{s} 1}=\left(0,2 \times 16,56 \times \tan 30^{\circ}\right) \times 1,884 \times 1,8=6,48 \mathrm{KN}$

$\mathrm{Q}_{\mathrm{s} 2}=\left(0,2 \times 99,06 \times \tan 30^{\circ}\right) \times 1,884 \times 15,7=338,34 \mathrm{KN}$

$\mathrm{Q}_{\mathrm{s} 1}=\left(0,2 \times 175,50 \times \tan 30^{\circ}\right) \times 1,884 \times 2,5=95,45 \mathrm{KN}$

$\Delta \mathrm{Q}_{\mathrm{s}}=6,48+338,34+95,45$

$\Delta \mathrm{Q}_{\mathrm{s}}=440,27 \mathrm{KN}$

c). Kapasitas Kuat Dukung Ultimit

$$
\begin{aligned}
\mathrm{Q}_{\mathrm{u}} & =\mathrm{Q}_{\mathrm{b}}+\mathrm{Q}_{\mathrm{s}} \\
& =991,93+440,27 \\
& =1432,20 \mathrm{KN}
\end{aligned}
$$

3). Untuk tiang bor berdiameter $80 \mathrm{~cm}(0,8 \mathrm{~m})$

a). Tahanan Ujung Ultimit

$\mathrm{Q}_{\mathrm{b}}=\mathrm{A}_{\mathrm{b}} \cdot \mathrm{q}_{\mathrm{b}}$

$\mathrm{q}_{\mathrm{b}}=\sigma_{\mathrm{r}} \cdot \mathrm{N}_{\mathrm{q}} *$

Nilai $\mathrm{N}_{\mathrm{q}} *$ didapat dari gambar 11 hubungan $\mathrm{L} / \mathrm{D}-\mathrm{N}_{\mathrm{q}} *$, Nilai $\mathrm{N}_{\mathrm{q}} *=20$

$\mathrm{q}_{\mathrm{b}}=175,50 \times 20$

$$
\begin{aligned}
& =3510 \mathrm{KN} / \mathrm{m}^{2} \\
\mathrm{~A}_{\mathrm{b}} & =1 / 4 \pi(\mathrm{d})^{2} \\
& =1 / 4 \pi(0,8)^{2} \\
& =0,5024 \mathrm{~m}^{2} \\
\mathrm{Q}_{\mathrm{b}} & =\mathrm{A}_{\mathrm{b}} \cdot \mathrm{q}_{\mathrm{b}} \\
& =0,5024 \times 3510 \\
& =1763,42 \mathrm{KN}
\end{aligned}
$$

b). Tahanan Gesek Ultimit

$\mathrm{Q}_{\mathrm{s}}=\mathrm{f}_{\mathrm{av}} . \mathrm{S} . \mathrm{L}$

$\mathrm{f}_{\mathrm{av}}=\left(\mathrm{K} \sigma_{\mathrm{r}}, \tan \delta\right)$. S.L

$\delta=\Phi=30^{\circ}$

$\mathrm{K}=0,2$ ( didapat dari grafik gambar 11)

Keliling tiang $=S=\pi \cdot d=\pi \times 0,8=2,512 \mathrm{~m}$

$\Delta \mathrm{Q}_{\mathrm{s}}=\mathrm{Q}_{\mathrm{s} 1}+\mathrm{Q}_{\mathrm{s} 2}+\mathrm{Q}_{\mathrm{s} 3}$

$\Delta \mathrm{Q}_{\mathrm{s}}=\mathrm{f}_{\mathrm{av1}} \cdot \mathrm{S} \cdot \mathrm{L}_{1}+\mathrm{f}_{\mathrm{av} 2} \cdot \mathrm{S} \cdot \mathrm{L}_{2}+\mathrm{f}_{\mathrm{av} 3} \cdot \mathrm{S} \cdot \mathrm{L}_{3}$

$\Delta \mathrm{Q}_{\mathrm{s}}=\left(\mathrm{K} \sigma_{\mathrm{r} 1}{ }^{\prime} \tan \delta\right) \cdot \mathrm{S} \cdot \mathrm{L}_{1}+\left(\mathrm{K} \sigma_{\mathrm{r} 2}{ }^{\prime} \tan \delta\right) \cdot \mathrm{S} \cdot \mathrm{L}_{2}+\left(\mathrm{K} \sigma_{\mathrm{r} 3}{ }^{\prime} \tan \delta\right) \cdot \mathrm{S} \cdot \mathrm{L}_{3}$

$\mathrm{Q}_{\mathrm{s} 1}=\left(0,2 \times 16,56 \times \tan 30^{\circ}\right) \times 2,512 \times 1,8=8,65 \mathrm{KN}$

$\mathrm{Q}_{\mathrm{s} 2}=\left(0,2 \times 99,06 \times \tan 30^{\circ}\right) \times 2,512 \times 15,7=451,11 \mathrm{KN}$ 


$$
\begin{aligned}
\mathrm{Q}_{\mathrm{s} 1} & =\left(0,2 \times 175,50 \times \tan 30^{\circ}\right) \times 2,512 \times 2,5=127,26 \mathrm{KN} \\
\Delta \mathrm{Q}_{\mathrm{s}} & =8,65+451,11+127,26 \\
\Delta \mathrm{Q}_{\mathrm{s}} & =587,02 \mathrm{KN}
\end{aligned}
$$

c). Kapasitas Kuat Dukung Ultimit

$$
\begin{aligned}
\mathrm{Q}_{\mathrm{u}} & =\mathrm{Q}_{\mathrm{b}}+\mathrm{Q}_{\mathrm{s}} \\
& =1763,42+587,02 \\
& =2350,44 \mathrm{KN}
\end{aligned}
$$

Dari ketiga ukuran diameter tiang bored pile dengan memakai 3 (tiga) metode perhitungan O'Neil \& Reese, Meyerhoff dan Coyle \& Castello dapat dilihat perbandingan kuat dukung ultimit pondasi tiang bored pile berdasarkan data $N$-SPT, perhitungan dengan metode Meyerhoff lebih optimis dibanding dengan memakai metode O’Neil \& Reese dan Coyle \& Castello.

Tabel 16. Perbandingan perhitungan nilai kuat dukung bored pile $\left(\mathrm{Q}_{\mathrm{u}}\right)$ dari ketiga metode O'Neil \& Reese, Meyerhoff dan Coyle \& Castello

\begin{tabular}{clccc}
\hline \multirow{2}{*}{ No } & \multirow{2}{*}{ Metode yang dipakai } & \multicolumn{3}{c}{ Nilai kuat dukung ultimit, $\mathrm{Q}_{\mathrm{u}}$} \\
\cline { 3 - 5 } & & $\varnothing 0,4 \mathrm{mN})$ & $\emptyset 0,6 \mathrm{~m}$ & $\varnothing 0,8 \mathrm{~m}$ \\
\hline 1. & O'Neil dan Reese & 476,21 & 803,52 & 1199,48 \\
2. & Meyerhoff & 1948,87 & 3828,60 & 6317,17 \\
3. & Coyle dan Castello & 734,37 & 1432,20 & 2350,44 \\
\hline
\end{tabular}

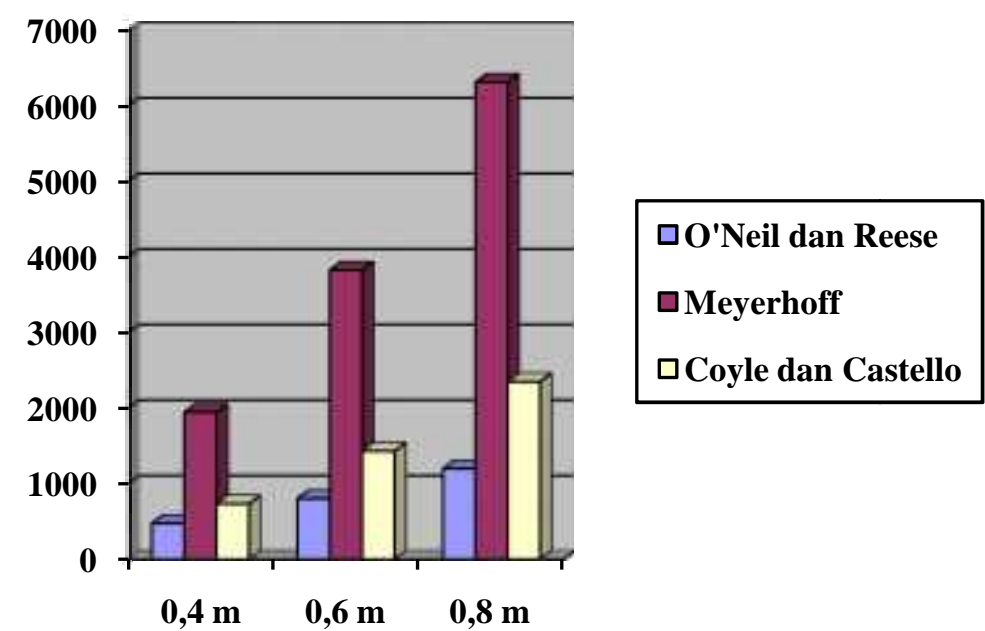

Gambar 13. Grafik perbandingan kuat dukung tiang bored pile antara perhitungan O’Neil \& Reese, Meyerhoff dan Coyle \& Castello

Dari ketiga ukuran diameter tiang bored pile dengan memakai perhitungan Metode Meyerhoff terhadap 2 (dua) data yang berbeda : data sondir dan data $N-S P T$. Data $N$-SPT lebih baik. 
Tabel 17. Perbandingan perhitungan nilai kuat dukung bored pile $\left(\mathrm{Q}_{\mathrm{u}}\right)$ dengan metode Meyerhoff berdasarkan data sondir dan N-SPT

\begin{tabular}{clrrr}
\hline \multirow{2}{*}{ No } & \multicolumn{1}{c}{ Data yang dipakai } & \multicolumn{3}{c}{ Nilai kuat dukung ultimit, $\mathrm{Q}_{\mathrm{u}}$} \\
\cline { 3 - 5 } & & $\varnothing 0,4 \mathrm{~m}$ & $\varnothing 0,6 \mathrm{~m}$ & $\varnothing 0,8 \mathrm{~m}$ \\
\hline 1. & Sondir & 2289,30 & 3785,83 & 4820,62 \\
2. & Standard Penetration Test & 1948,87 & 3828,60 & 6317,17 \\
\hline
\end{tabular}

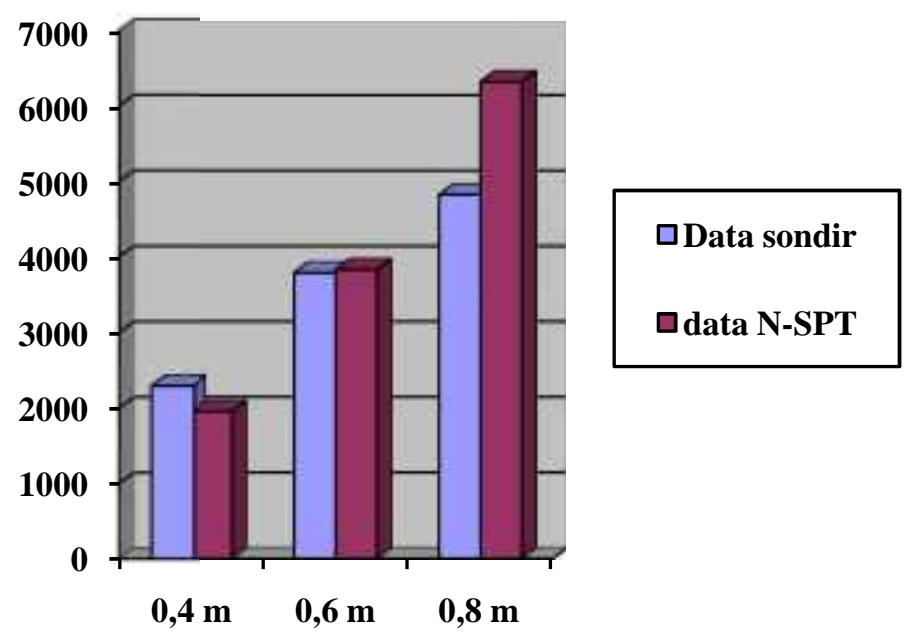

Gambar 14. Grafik perbandingan perhitungan kuat dukung tiang bored pile metode Meyerhoff dengan 2 (dua) data yang berbeda (sondir dan N-SPT)

\section{E. KESIMPULAN}

Berdasarkan hasil perhitungan perencanaan pondasi bored pile pada proyek pembangunan gedung dan perbengkelan 7 lantai di jalan Arengka Pekanbaru, maka dapat diambil beberapa kesimpulan :

1. Dengan data sondir dan ukuran diameter tiang bored pile yang berbeda dengan memakai 2 (dua) metode perhitungan Schmertmann \& Nottingham dan Meyerhoff dapat dilihat perbandingan kuat dukung ultimit pondasi tiang bored pile, persentase perhitungan dengan metode Schertmann dan Nottingham lebih optimis $\pm 6,24 \%$ dibanding dengan memakai metode Meyerhoff yang bersifat konservatif

2. Begitu pula dengan hasil perbandingan perhitungan kapasitas kuat dukung tiang bored pile dari data N-SPT dengan memakai metode O'Neil dan Reese, metode Meyerhoff dan metode Coyle dan Castello, metode O'Neil dan Reese lebih optimis dengan safety factor yang relatif lebih kecil.

3. Perhitungan kapasitas kuat dukung tiang bored pile yang lebih optimis dengan safety factor kecil akan berdampak pada efisiensi penggunaan material dan penghematan biaya konstruksi. 


\section{Daftar Pustaka}

Bowles J.E., 1991, Analisa dan desain Pondasi, Edisi keempat Jilid 1, Erlangga, Jakarta.

Bowles J.E., 1993, Analisa dan desain Pondasi, Edisi keempat Jilid 2, Erlangga, Jakarta.

Bowles J.E., 1996, Foundation Analysis and Design, McGraw-Hill Kogakusha, Ltd., Tokyo, Japan.

Das M.B., 1991, Principles of Foundation Engineering, Fourth Edition, California State University, Sacramento.

Hakam A., 2008, Rekayasa Pondasi, CV. Bintang Perdana, Sumatera Barat.

Hardiyatmo H.C., 1996, Teknik Pondasi 1, PT. Gramedia Pustaka Umum, Jakarta.

Hardiyatmo H.C., 2002, Teknik Pondasi 2, Edisi Kedua, Beta Offset, Yogyakarta.

Hardiyatmo H.C., 2010, Analisis dan Perancangan Fondasi, Edisi Pertama bagian II, Gadjah Mada University Press, Yogyakarta.

Irsyam M., Catatan Kuliah Rekayasa Pondasi Teknik Sipil dan Lingkungan, ITB, Bandung.

Prakash S. \& Sharma, D.H., 1990, Pile Foundation in Engineering Practice, Canada.

Sosarodarsono S. \& Nakazawa K., 1983, Mekanika Tanah Dan Teknik Pondasi, PT. Pradnya Paramita, Jakarta. 